\title{
Contribution of environmental and spatial factors to the structure of stream fish assemblages at different spatial scales
}

\author{
$\operatorname{AUTHOR}(\mathrm{S})$ :
}

Nakagawa, Hikaru

\section{CITATION:}

Nakagawa, Hikaru. Contribution of environmental and spatial factors to the structure of stream fish assemblages at different spatial scales. Ecology of Freshwater Fish 2014, 23(2): 208-223

\section{ISSUE DATE:}

2014-04

URL:

http://hdl.handle.net/2433/199856

\section{RIGHT:}

This is the peer reviewed version of the following article: Nakagawa, H. (2014), Contribution of environmental and spatial factors to the structure of stream fish assemblages at different spatial scales. Ecology of Freshwater Fish, 23: 208-223, which has been published in final form at http://dx.doi.org/10.1111/eff.12070. This article may be used for non-commercial purposes in accordance with Wiley Terms and Conditions for Self-Archiving.; This is not the published version. Please cite only the published version.; この論文は出版社版でありません。引用の際には出版社版をご確認じ 利用ください。 
1 Title: Contribution of environmental and spatial factors to the structure of stream fish assemblages

2 at different spatial scales

3 Author: Hikaru Nakagawa

4 Email-address: nakagawa@terra.zool.kyoto-u.ac.jp

5 Telephone: $075-753-4077$

6 Fax: $075-753-4100$

7 Address: Graduate School of Science, Kyoto University, Kitashirakawa-Oiwake-cho, Sakyo-ku,

8 Kyoto-city, Kyoto 606-8502, Japan

9 Short title: Scale-dependent contribution of environmental and spatial factors in fish assemblages

10 Key words: hierarchical river structures, habitat selection, dispersal process, scale dependency,

11 source-sink dynamics

12

13 


\section{Abstract}

15 To compare the contributions of environmental and spatial factors in structuring assemblages of

16 temperate stream fish on different spatial scales, I evaluated the distance decay of fish assemblage

17 similarity and correlations among species compositions, environmental factors and geographical

18 locations at medium (inter-reach scale, spatial extent $40 \mathrm{~km}$ ) and fine (inter-microhabitat scale,

19 spatial extent $<200 \mathrm{~m}$ ) scales. Partial redundancy analysis and variation partitioning indicated that

20 the ordinal rank of the relative importance of environmental and spatial factors differed among

21 scales. At the medium scale, the distance decay of similarity of species composition was steep at

22 approximately $>10-\mathrm{km}$ scale, and the assemblage structure was simply explained by the distance

23 between sites and several environmental factors (e.g. elevation and current velocity). In contrast,

24 the distance between microhabitats explained only a small portion of the variance in species

25 composition at the fine scale, and fish assemblages were affected by several spatial patterns of

26 habitat (or some environmental features associated with those spatial patterns). Environmental

27 factors at the fine scale (e.g. substratum characteristics and presence/absence of cover) correlated

28 with each other and were spatially structured, and their contribution to species variance was

29 smaller than that at the medium scale. These results provide evidence for scale-dependent

30 alternation of the rank of the relative importance of environmental and spatial factors in structuring

31 assemblages of stream fishes via the turnover of crucially contributing factors from medium to fine 
32

33

\section{$34 \quad$ Introduction}

35 The contribution of 'environmental factors' and 'spatial factors' in determining community

spatial scales.

structure is currently an important topic in community ecology. This dichotomy was recently

synthesised in a metacommunity theory (Leibold et al. 2004; Cottenie 2005). Leibold et al. (2004)

categorised metacommunity theories into 4 paradigms (neutral model, patch dynamics, mass

effects and species sorting), questioning whether the structuring of local communities is affected

by dispersal limitation, interspecific interactions and habitat heterogeneities. In a river, various

biotic and abiotic environments exhibit characteristic spatial structures across multiple scales (e.g.

channel networks at the river system scale, directional 1-dimensional structure at the segment scale

and environmental patches at the reach and microhabitat scales; Frissell et al. 1986; Montgomery

\& Buffington 1997) and hierarchical structures are expected to affect both environmental and

spatial processes at each scale. Therefore, to evaluate the contributions of environmental and

spatial factors in the determination of a riverine community structure, consideration of scale

dependency is essential (Holyoak et al. 2005; Heino 2011).

Several studies have examined the contributions of environmental and spatial factors in assemblages of fishes in streams and demonstrated taxonomic or functional group dependency 
50 (Hoeinghaus et al. 2007), the effect of non-native species (Sály et al. 2011), temporal variability

51 (Erös et al. 2012), region dependency (Kautza \& Sullivan 2012) and spatial scale dependency.

52 Spatial scale dependency is considered to be the most important factor and has been repeatedly

53 examined (Magalhães et al. 2002; Mykrä et al. 2007; Heino 2011; Sály et al. 2011). However,

54 many previous studies have considered the changes in contribution from large to medium spatial

55 scales (i.e. variation among regions, water systems, segments and reaches) and not from medium

56 to fine scales (i.e. variation among microhabitats).

As with the change from large to medium scales, the contribution of environmental and

58 spatial factors in stream assemblages is also likely to change from medium to fine scales. Previous studies have demonstrated that environmental factors decrease their contribution and spatial factors display the opposite pattern in structuring stream assemblages, with a decrease in spatial scale from large to medium (Magalhães et al. 2002; Mykrä et al. 2007). This trend is a consequence of the large contribution of source-sink effects (mass effects or rescue effects;

63 Amarasekare 2003) at the medium scale and the small (but significant) contribution of

64 biogeographical backgrounds at the large scale (Magalhães et al. 2002). When scaling down from

65 medium to finer scales, the contribution of environmental factors is predicted to be large across all spatial scales via the turnover of corresponding environmental factors, because many previous 
68 composition across inter-regional to inter-microhabitat scales (Matthews 1998; Wang et al. 2003;

69 Durance et al. 2006; Heino 2011). In contrast, the contribution of spatial factors is predicted to

70 decline at finer spatial scales because the spatial processes that determine stream assemblage

71 structures strongly associate with the dispersal of individuals that are less constrained by distance

72 at fine scales [e.g. neutral processes at river system scales (Muneepeerakul et al. 2008) and mass

73 effects at reach or segment scales (Falke \& Fausch 2010)]. For these reasons, I predicted that the

74 contribution of environmental factors is larger and that of spatial factors is smaller when the

75 spatial scale is decreased (i.e. the reverse pattern of the scale dependency from large to medium

76 scales). However, previous studies on the contributions of environmental and spatial factors in

77 stream assemblages were based on presence/absence data or total individual numbers in reaches or

78 larger sampling units (Magalhães et al. 2002; Mykrä et al. 2007; but see Sály et al. 2011 who

79 compared the presence/absence and relative abundance data at medium and large scales) the scale

80 dependency from medium to fine scale has not yet been examined.

Therefore, I conducted a quantitative and detailed investigation of fish distribution and environmental factors at medium and fine scales by direct underwater observations. I predicted

83 that environmental factors would be significant in assemblage structuring at both scales by

84 alternating the responsible factors between the 2 scales. In contrast, spatial factors would be

85 significant only at the medium scale because dispersal constraints among habitat patches would 
86 decrease at the fine scale. Based on the above predictions, the contribution of the environment

87 would therefore increase and the contribution of space would decrease with a reduction in spatial

88 scale. The contributions of individual factors, for both environmental and spatial factors, in

89 assemblage structuring using partial redundancy analysis (partial RDA) were examined. The

90 effects of dispersal processes were also examined by evaluating the distance decay of both species

91 composition and habitat similarity. The contributions of environmental and spatial factors were

92 evaluated using variation partitioning (VP). Based on these results, I demonstrate scale

dependency of the contributions of environmental and spatial factors in describing the variance of

94 assemblages of fishes in stream from medium to fine spatial scales and discuss the key processes

95 contributing to assemblage structuring.

\section{Materials and methods}

99 Research area

100 The study was conducted along the main stem of the Yura River, from the headwater to about 40

$101 \mathrm{~km}$ downstream in the lower reaches, in the northern part of Kyoto Prefecture, western Japan (Fig.

102 1a, b and c). The research area is separated from the lower part of the river by a large dam. The

103 Yura River flows from the Sugio Ridge (750 m a.s.l.), located on the border between Kyoto and 
104 Fukui prefectures, and the river course has a length of about $146 \mathrm{~km}$ and a catchment area of about

$1051880 \mathrm{~km}^{2}$. The regional climate is warm-temperate with monsoon effects. At the location of the

106 upper quarter of the research area $\left(35^{\circ} 18^{\prime} \mathrm{N}, 135^{\circ} 43^{\prime} \mathrm{E}, 356 \mathrm{~m}\right.$ a.s.1.), the annual mean temperature

107 is $11.9^{\circ} \mathrm{C}$, annual precipitation is $2298 \mathrm{~mm}$ and snow depth in winter is approximately $1 \mathrm{~m}$. The

108 catchment area in the upper part of the research area (0-15 km from the headwater) is covered by

109 conifer plantations of Cryptomeria japonica and deciduous broad-leaved forests dominated by

110 Fagus crenata and Quercus crispula (data from Ashiu Forest Research Station, Field Science

111 Education and Research Center, Kyoto University, http://www.fserc.kais.kyoto-u.ac.jp/asiu/).

112 Residential and agricultural use in the catchment area in the lower part of the research area (15-40

$113 \mathrm{~km}$ from the headwater) is less than 5\% (data from Nantan City, Kyoto, Japan), and I therefore

114 considered that the effects of these uses on fish species composition were negligible. Artificial

115 protective structures on riverbanks are relatively rare, and most areas of the riverbanks are

116 bordered by forests. Some sediment control dams exist in the middle part of the research area, but

117 all dams have a fishway, and the species composition of fish did not show sudden changes at any

118 dam in a preliminary analysis (see also Results). Thus, I considered that artificial or natural

119 structures restricting dispersal of fishes probably do not exist in the main stream from the

120 headwater to the dam $40 \mathrm{~km}$ below. 
123 The spatial patterns of fish assemblages at medium (inter-reach scale, spatial extent $40 \mathrm{~km}$ ) and

124 fine (inter-microhabitat scale, spatial extent <200 m) scales were examined. In my research area,

125 the medium and fine scales reflect the inter-reach (intra-segment or intra-river longitudinal) scale

126 and the inter-microhabitat (intra-reach) scale, respectively, in the hierarchical river structure

127 (Frissell et al. 1986; Allan \& Castillo 2007). A reach is defined as a repeating sequence of channel

128 units (such as a riffle-pool-run sequence; Frissell et al. 1986; Allan \& Castillo 2007). In the Yura

129 River, the length of 1 reach (riffle-pool-run sequence) is approximately $50 \mathrm{~m}$ at the upper sites in

130 the research area and $200 \mathrm{~m}$ at the lower sites on average.

131 A microhabitat is recognised as decimetre-scale environmental sets that are patchily

132 distributed within a reach, such as deep locations, boulders, crevices in the bedrock or cover in the

133 riverbank (Frissell et al. 1986).

134

135 Sampling sites and observation plots

136 Twenty-one sampling sites that represented all the river structures contained within the research

137 area were established: sites 1 (uppermost) to 21 (lowest) (Fig. 1c). No sampling sites were

138 established in the river between 4 to $10 \mathrm{~km}$ from the headwater because of access difficulties. The

139 Yura River originates from a spring in the forest floor. The uppermost site of the research area was 
$1401.5 \mathrm{~km}$ downstream from the origin. The lowest sampling site was located just upstream of the

141 dam reservoir.

142

Ten line transects were set perpendicular to water flow along the channel at each sampling

143 site (Fig. 1d). The interval between transects was adjusted according to river size: 5-m intervals at

144 the upper 4 sites (sites 1-4); 20-m intervals at sites 14, 20 and 21 and 10-m intervals at all other

145 sites. Each sampling site included at least 1 reach (1-3 reaches). Plots were established along each

146 transect at regular intervals (4-8 plots per transect; Fig. 1d). Plots were the minimum unit of

147 observation and measurement. The number of observation plots along the transects was adjusted

148 according to channel width: 4 plots at the upper 4 sites (sites 1-4; mean wet width $<5$ m), 8 plots

149 at sites 14, 20 and 21 (mean wet width >20 m) and 6 plots at the other sites (mean wet width 5-20

$150 \mathrm{~m})$. A red-coloured sounding lead was placed at the centre of each observation plot as a landmark

151 for fish observation and environmental measurements.

152

153 Fish observations

154 Fish observations were conducted in the summer from 20 August to 27 September 2009. During

155 this season, the water temperature of the river is at its annual maximum, and all fish species are

156 active (Nakagawa, unpublished data). Observations were conducted by snorkelling during the day

157 (10:00-15:00) and night (22:00-3:00), because some fish species are active at night. Water 
158 temperature was measured at the start time of each observation. Snorkelling observations were

159 conducted by the line-transect method using the following procedure: First, I dived into the right

160 or left side of a stream channel and moved to $1 \mathrm{~m}$ downstream of a transect. Five minutes later, the

161 fish showed normal behaviour, I quietly moved along the transect and observed the fish. When an

162 individual fish was found, I recorded its species and the nearest landmark lead. All observations

163 were conducted by the same person (HN). The observation time was approximately 20 min

164 (including waiting time) per transect. A waterproof hand light and headlight were used for night

165 observations. Because diet and habitat shifts during larval and juvenile periods occur in some

166 target species (Nakamura 1969), data for larval fish were excluded from the analysis.

167 The number of individuals of each species observed at a plot at each sampling site (4 plots at

168 sites 1-4, 6 plots at sites 5-13 and 15-19 and 8 plots at sites 14, 20 and 21) was used to determine

169 fish distribution data at the fine scale. In the research area, 27 fish species were observed in total

170 (Nakagawa, unpublished data). Although the bluegill sunfish, Lepomis macrochirus, was

171 introduced from North America, this species was included in the analysed data set because it

172 became established in this river at least 14 years prior to the study (National Census on River

173 Environments of Japan 1993); hence, its distribution is not likely to be restricted by its initial

174 location of introduction. The largemouth bass, Micropterus salmoides, was also introduced from

175 North America, but I did not observe this species in the research area, probably because it is 
176 primarily lentic and restricted to dam reservoirs. Anguilla japonica, Plecoglossus altivelis and

177 Oncorhynchus masou were excluded from the analysed data set as they are introduced annually by

178 a local fishery cooperative, and I could not determine the innate distribution of these species.

179 Among the material species in this study, Zacco platypus, Cyprinus carpio, Carassius auratus and

180 L. macrochirus occupy the dam reservoir (National Census on River Environments of Japan

181 1993); however, Z. platypus mainly occupies stream habitats (Nakamura 1969), and the other

182 species are rare in the upper to middle reaches of the Yura River (see Results). Therefore, the

183 effect of the dam reservoir seems to be small in this research. The total number of individuals of

184 each species at each sampling site was used for fish distribution data at the medium scale. Day and

185 night data were pooled.

186

187

Environmental data

188 Environmental factors were categorised into medium- and fine-scale descriptors on the basis of

189 previous studies that referred to the spatial scales critical for habitat selection by fish (Table 1). For

190 example, in general, water temperature gradually increases from upper to lower reaches at the

191 kilometre scale, and therefore the distribution of a fish species determined by temperature

192 tolerance would be responsive at this scale (Fausch et al. 1994). Water temperature was therefore

193 categorised as a medium-scale factor. Pinpoint habitat patches such as cover and boulders are used 
194 as short-term habitats for refuge or foraging sites (Sechnick et al. 1986; Fuselier \& Edds 1995;

195 Nakagawa et al. 2012); thus, these were considered fine-scale factors.

196 Fine-scale data (i.e. water depth, current velocity, substratum characteristics and

197 presence/absence of cover) were measured at the point of each landmark lead (i.e. each

198 observation plot) after fish observations. Water depth was measured with accuracy of $1 \mathrm{~cm}$ using a

199 metre stick. Current velocity was measured at $60 \%$ water column depth using a portable

200 tachometer (Model 3651 Pocket Tachometer, Cosmo-Riken, Osaka, Japan). To measure substrate

201 characteristics, a $50 \times 50$-cm quadrat with $10 \times 10$-cm cells (total of 25 cells) was placed on a

202 landmark. Furthermore, the major substrate type was recorded, which was characterised by

203 sediment particle size, in each cell based on the Wentworth-Udden particle scale ( $<2 \mathrm{~mm}$, sand;

204 2-4 mm, granules; 5-64 mm, pebbles; 65-256 mm, cobbles; >256 mm, boulders; bedrock;

205 Wentworth 1922). Cover was defined as over-hanging branches and leaves of terrestrial plants that

206 were more than $50 \mathrm{~cm}$ long.

207 A portion of the medium-scale data was calculated as the mean of measurements for all

208 observation plots or transects included in each sampling site. This method was applied for water

209 depth, current velocity, substrate characteristics, presence/absence of cover and channel width. The

210 other portion of medium-scale data (the gradient of the river bed at each sampling site) was

211 obtained from a 1:25,000 map published by the Geospatial Information Authority of Japan. The 
212 gradient of the river bed was represented as the mean of 30 gradient measurements for 100-m

213 intervals within $\pm 1.5 \mathrm{~km}$ of the upper and lower reaches around the sampling site. Water

214 temperatures measured at each observation were averaged. Flow rate was calculated as the product

215 of the means of water depth, current velocity and channel width at each sampling site.

\section{Spatial data}

218 Spatial variables at each spatial scale were constructed using Moran’s eigenvector mapping

219 (MEM) technique. MEM describes the spatial structures of species composition by the eigenvalues

220 and eigenvectors that represent the spatial relationships between sampling points across various

221 spatial scales (Dray et al. 2006). The MEM approach offers advantages over direct geographical

222 coordinate or trend-surface (i.e. polynomial) approaches in that MEM ensures independence

223 between spatial variables and detects wider-range spatial structures. These methods have been

224 reviewed in detail by Okuda et al. (2010) (see also Borcard \& Legendre 2002; Borcard et al. 2004;

225 Dray et al. 2006).

226 Spatial patterns of the observed assemblages were analysed separately for the medium and

227 fine spatial scales. For the medium scales, the 21 sampling sites on the main stream were

228 approximated by points on a 1-dimensional line, such that the order and interval of the points

229 reflected the location of the sampling sites (see upper figure in Appendix 1). For the fine scale, 
230 disposition of the observation plots was approximated in each sampling site by $10 \times 4$ grids with a

231 10:1 aspect ratio at the upper 4 sites (sites $1-4$ ); $10 \times 8$ grids with a 10:1 aspect ratio at sites 14, 20

232 and 21; and $10 \times 6$ grids with a 10:1 aspect ratio at the other sites (see the lower figures in

233 Appendix 1). A spatial weighting matrix (SWM) was constructed for the medium-scale data and

23421 SWMs for the fine-scale data from the distances of neighbouring sampling sites and then from

235 the distances from each of the neighbouring observation plots within a sampling site, respectively

236 (Dray 2010). Moran’s eigenvectors (MEVs) were calculated from an SWM and used as the spatial

237 variables. An MEV exhibited a wave-like spatial pattern when plotted on the location of the

238 sampling sites or observation plots (see Results) and represented the autocorrelation patterns of

239 these sites and plots (Dray 2010).

240

241 Tests of distance decay in fish assemblages and environmental similarities

242 The similarity indices of species composition and habitat characteristics were calculated between

243 sampling sites at the medium scale and between observation plots at the fine scale to analyse the

244 decay of these similarities with distance. The distance was defined as the straight-line distance

245 between pairs of observation plots at the fine scale and as the distance along the river between

246 pairs of sampling sites at the medium scale. At the fine scale, similarities between $<5 \mathrm{~m}$ and $>50 \mathrm{~m}$

247 distant plots were eliminated from the analysis because they did not exist in common at all 
248 sampling sites. The Bray-Curtis similarity index (1- the Bray-Curtis dissimilarity), based on the

249 number of individuals of each species at sampling sites or observation plots, was used to express

250 the similarity of species composition. The correlation between the similarity of species

251 composition and distance was examined using Mantel tests at each scale. The environmental

252 characteristics measured at the medium and fine scales (Table 1) were used to calculate the habitat

253 similarity at each scale. For evaluating habitat similarity, principal components analysis was

254 conducted on the basis of the environmental characteristics for each spatial scale and obtained

255 principal component (PC) scores of observation plots for PC 1-4 at the medium scale and PC 1-5

256 at the fine scale; these explained $>80 \%$ of the total variance in environmental characteristics for

257 each spatial scale. Subsequently, the multidimensional Euclidian distance $(D)$ of the PC scores was

258 used to calculate the index of habitat similarity. By using the transformation $1-D /(1+D), D$ has

259 been converted into a similarity index ranging from 0 to 1 . The correlation between habitat

260 similarity and distance was examined using Mantel tests at each spatial scale.

\section{Multivariate analysis}

263 In the multivariate analyses of VP procedure, the Hellinger transformation (rows of the data set are

264 standardised by their row sum and then a square root transformation, Legendre \& Gallagher 2001)

265 was applied to data for species composition in each plot or each site to adjust the difference in the 
266 size of observation units and avoid the horseshoe bias (Peres-Neto et al. 2006). VP analysis was

267 conducted to evaluate the contributions of environmental and spatial factors in determining spatial

268 patterns of assemblages at different spatial scales. The total variation contained in the distribution

269 data for fishes was segregated into unique environmental and spatial components using

270 redundancy analysis (RDA) based on a VP approach (Borcard et al. 1992). RDA is a constrained

271 ordination technique and serves as a multivariate extension of linear regression analysis (Legendre

272 \& Legendre 1998; Beisner et al. 2006; Okuda et al. 2010). The environmental variables were

273 log-transformed (Stewart-Koaster et al. 2007; Erős et al. 2009). A forward selection technique was

274 conducted according to Blanchet et al. (2008) before RDA for the environment and spatial

275 variables to find the statistically relevant variables. VP was calculated from 3 RDAs as follows.

276 The first RDA uses sets of both environmental and spatial variables and obtains the total variation

277 of a distribution data for fishes explained by environmental and spatial variables, expressed as [E

$278+\mathrm{S}]$. The second RDA calculates the fraction [E] that is explained by environmental variation,

279 involving co-effects of spatial variables. The third RDA calculates the fraction [S] explained by the

280 spatial variation, including co-effects of environmental variables. [E + S], [E] and [S] were

281 adjusted for a multiple coefficient of determination ( $\mathrm{R}^{2}$ adj. $)$ according to Peres-Neto et al. (2006).

282 Note that, in some cases (e.g. small sample size, large number of explanatory variables), negative

283 values can be obtained. The other fractions can be obtained as follows: the fraction of variation 
284 explained by environmental factors independent of spatial factors is $[\mathrm{EP}]=[\mathrm{E}+\mathrm{S}]-[\mathrm{S}]$, the

285 fraction of variation explained by spatial factors independent of environmental factors is $[\mathrm{SP}]=[\mathrm{E}$

$286+\mathrm{S}]-[\mathrm{E}]$, the fraction of variation explained by correlations between environmental and spatial

287 factors is $[E S]=[E]+[S]-[E+S]$, and the residual fraction of variation is $[R]=1-[E+S]$.

288 [EP] and [SP] indicate the independent effects of observed environmental conditions (associated

289 with niche explanations) and spatial arrangement (representing local dispersal processes or an

290 environmental factor associated with that spatial pattern), respectively, in determining the spatial

291 variation in species composition. [ES] represents the fraction explained by variables that cannot be

292 statistically divided into environmental and spatial factors (Peres-Neto et al. 2006). [R] is the

293 unexplained spatial variation in species composition and includes the effects of unmeasured

294 environmental factors and stochastic mechanisms. The VP approach has the potential risk of

295 underestimating the relative contributions of environmental factors when important environmental

296 factors are not included in the data set (Gilbert \& Bennett 2010; Smith \& Londholm 2010). For

297 example, river-bank characteristics were not included as environmental factors because of their

298 explicit correlations with the spatial arrangements of observation plots. Therefore, possible

299 spurious correlation of a spatial factor must be considered when interpreting the results of VP

300 (Gilbert \& Bennett 2010; Smith \& Londholm 2010). However, despite this problem, the VP

301 approach is a good tool in the first step of partitioning out environmental and spatial components 
302 from the total variation in species composition using appropriate adjustments [e.g. the unimodal

303 distribution of species (Peres-Neto et al. 2006; Legendre \& Gallagher 2001), the inflation of

304 variance (Blanchet et al. 2008) and sampling density (Peres-Neto et al. 2006)].

305 The significance of the testable variance fractions (i.e. [EP], [SP] and [ES]) was tested using

306 permutation tests with 9999 randomisations of the correspondence between the spatial patterns of

307 species composition and each set of environmental and spatial predictors according to the tutorial

308 of the statistical software CANOCO (Borcard et al. 1992; Leps \& Smilauer 2003). For each spatial

309 and environmental predictor at the fine scale, significance was also tested for each sampling site

310 because the selected predictors differed among sites. $P$-values were adjusted by the number of

311 variables in each VP or partial RDA using the Bonferroni method.

312 Forward selection of variables, VP, permutation tests, partial RDA and MEM were

313 performed using the statistical software R (R Development Core Team 2010) with the add-on

314 packages 'vegan' (Oksanen et al. 2008), 'spacemakerR' (Dray 2010) and 'packfor' (Blanchet et al.

315 2008).

317 Results

318 Fish species composition and its distance decay

319 A total of 9520 individuals of 27 fish species were observed, and data for 9402 individuals of 24 
320 species were used for analyses (Appendix 2). Uneven distribution patterns biassed towards the

321 upper, upper-middle, lower-middle or lower reaches at the medium scale were observed in some

322 fish species; thus, species composition changed along the river course (Fig. 2). Several fish species

323 exhibited bell-curve-like patterns of distribution, having a centre of distribution with high

324 population density at a certain position in the river course and a skirt of distribution with low

325 population density (Fig. 2).

326 Similarity in species composition was significantly correlated with the distance at the

327 medium scale (Mantel test, $r=0.772, P=0.001$, Fig. $3 a)$ but not at the fine scale $(r=0.014, P=$

328 0.424, Fig. 3b). The decay of species similarity was particularly clear at $10 \mathrm{~km}$ or larger scales (Fig.

329 3a).

330

331 Habitat environments and their distance decay

332 In general, at the medium scale, water temperature, gradient of the river bed, flow rate and mean

333 width of the river channel simply decreased or increased from upper to lower reaches. In contrast,

334 other factors (e.g. mean water depth and mean current velocity) did not demonstrate such simple

335 patterns along the upper-lower locations of the river (Appendix 3). Distance decay in similarity of

336 habitat environment was detected at both the medium scale (Mantel test, $r=0.629, P=0.001$; Fig.

337 3c) and the fine scale (Mantel test, $r=0.075, P=0.040$; Fig. 3d), but the effect was much weaker 
338 for the latter. In contrast to the distance decay patterns in species composition similarity, habitat

339 similarity was nearly constant around the 10-20-km spatial scale.

340

341 Partitioning of environmental and spatial factors and significance of individual factors

342 I obtained data sets for species composition at the fine scale, environmental variables and spatial

343 variables at 1063 observation plots, excluding plots where no fish were observed. According to the

344 VP analysis, the predictor variables explained $85.98 \%$ of the total variation in species composition

345 at the medium scale and the mean variation of 36.5\% at the fine scale (Tables 2 and 3).

346 At the medium scale, 3 environmental variables (elevation, water temperature and mean

347 current velocity) and 6 spatial variables (MEV 1-6) were selected (Table 2). At the fine scale, the

348 number of selected environmental variables was 2 at site 18, 1 at sites 2, 3, 6, 7, 9, 11-15 and 21

349 and none at the others (Table 3). The number of selected spatial variables varied from 1 to 13

350 among sites (Table 3).

351

The fractions of variation explained by pure environmental predictors [EP], pure spatial

352 predictors [SP] and by both environmental and spatial predictors [ES] changed with the spatial

353 scale (Tables 2 and 3). The results of permutation tests indicate the significance of [ES] at both

354 scales, but [ES] explained a larger fraction (68.2\%) at the medium scale compared with the mean

355 value of the fine scale (4.2\%). In each site examination the fine scale, [ES] was significant at 10 
356 of the 21 sites. [SP] explained the largest portion (31.5\% of the mean) at the fine scale and the

357 second largest portion (12.6\%) at the medium scale and was significant at both scales. At all

358 sampling sites, with the exception of site 14, [SP] significantly explained the variation in species

359 composition at the fine scale. [EP] explained a relatively small portion of the variation at both

360 scales (5.2\% and $1.0 \%$ of the mean at the medium and at the fine scales, respectively) and was

361 significant only at the medium scale. [EP] was significant at 3 of 21 and 7 of 21 sites with and

362 without Bonferroni adjustment.

363

The results of partial RDA excluding the effect of spatial variables indicated a significant

364 effect of elevation and mean current velocity at the medium scale (Table 2). At the fine scale, the

365 significance of individual variables (water depth, current speed, several substrate characteristics or

366 presence/absence of cover) was indicated at 6 of 21 sites, but a consistent pattern among sites was

367 not detected (Table 3). The elevation and mean current velocity at the medium scale, water depth,

368 current speed, several substrate characteristics and the presence/absence of cover at the fine scale

369 were significantly correlated with the number of individuals of several fish species in sampling

370 sites or observation plots (general linear model, $P<0.05$; see also Appendix 4).

371 The results of partial RDA excluding the effect of environmental variables indicated

372 significant effects of MEVs 1, 2 and 3 at the medium scale (Table 2). MEVs 1, 2 and 3 exhibited

373 fluctuating patterns, with wavelengths ranging from approximately 10 to $20 \mathrm{~km}$ (Fig. 4). Their 
374 peak positions and fluctuating patterns corresponded well with the distribution of some fish

375 species (e.g. MEV 1 was significantly correlated with the distributions of Zacco temminckii,

376 Pungtungia herzi and Squalidus gracilis; $r^{2}=0.58,0.55$ and 0.51, respectively; all $P<0.001$; Figs

377 2c and 4).

At the fine scale, the number of significant spatial variables ranged from 0 to 2 and 0 to 6

379 with and without Bonferroni correction, respectively, in the partial RDA (Table 3). Three spatial

380 variables commonly explained a large proportion of the variation in species composition across

381 several sites (MEV 2 at sites 6, 8, 10, 12 and 19; MEV 4 at sites 12 and 16-19 and MEV 45 at

382 sites 5-8, 10, 13, 17 and 18). These spatial variables exhibited characteristic spatial patterns, i.e.

383 horizontal patterns relative to a river channel for MEVs 2 and 4 or patch-like patterns for MEV 45

384 (Fig. 5).

385

386 Discussion

387 Scale dependency of the contribution of environmental and spatial factors across medium to fine

388 scales

389 Contrary to my original prediction, the results of VP analysis indicated the contribution of spatial

390 factors associated with the distance between sites or an arrangement of local habitats in the

391 determination of fish species composition at both the medium and fine spatial scales in the middle 
to upper Yura River. Results at the medium spatial scale were consistent with those of previous studies in which dispersal processes such as dispersal limitation, mass effects and patch dynamics

394 played key roles in determining the distribution of several species of stream organisms (Cottenie 2005) and fish communities in a river (Magalhães et al. 2002; Falke \& Fausch 2010; Winemiller et al. 2010). However, in the present study, the distance decay of the similarity of species composition was steeper at the medium scale (especially $\geq 10 \mathrm{~km}$ ) than that at the fine scale. These results indicate that the dispersal of fish individuals was strongly determined by the distance between local habitat patches at the medium scale. The differing patterns observed for the distance decay of species composition and that of habitat characteristics at the medium scale also support

401 dispersal processes rather than habitat selection of fishes. The distance decay of species composition at medium spatial scales (spatial extent about 4-50 km) has also been reported in

403 several stream fish assemblages (Magalhães et al. 2002; McGarvey \& Ward 2008). In contrast, the 404 practically negligible distance decay at the fine scale indicates that distance between microhabitats 405 explained only a portion of the contribution of spatial predictors in structuring assemblages.

406 Several fine-scale spatial predictors showed 2-dimensional patterns (i.e. horizontal patterns 407 relative to a river channel and patch-like patterns) that were significantly associated with the 408 variation in species composition at several sampling sites. This result may be related to the home 409 ranges of fish as discussed in the next section. 
411 significant at medium spatial scales when the effect of correlations with spatial predictors was

412 removed. This finding supports classical niche theories, such as habitat template theory

413 (Southwood 1977; Townsend \& Hildrew 1994) and species sorting theory (MacArthur 1958;

414 Pianka 1966), in which interspecific variation in habitat niches is considered a key factor in

415 structuring communities at medium scales. In contrast, the variation of assemblage structures

416 explained by environmental factors was small at the fine scale, and the largest part of that could

417 not be divided into environmental and spatial factors. Subsequently, in the forward selection of

418 environmental variables, only 1 variable was selected at most sampling sites. These patterns

419 indicate that environmental gradients of microhabitats in a reach were strongly spatially structured

420 and correlated with each other. Therefore, in contrast to the medium scale, pure environmental

421 processes may explain only a limited part of the assemblage structure of stream fishes at the fine

422 scale. The scale dependency of the contribution of environmental factors in the determination of

423 fish distribution has been reported for individual species across various spatial scales (Fausch et al.

424 1994; Inoue et al. 1997; Perkin \& Gido 2011), but for fish assemblages, only large to medium

425 scales have been considered and not medium to fine scales (Wang et al. 2003; Durance et al.

426 2006). 
428 Processes determining species composition at each spatial scale

429 1. Medium scale

430 At the medium scale, the spatial variation in species composition was largely explained by

431 distance, reflecting the distance decay of species composition and bell-curve-like distribution

432 along the river course for some fish species. These patterns are typically caused by dispersal

433 constraints of individuals by distance or an environmental factor that is strongly structured

434 spatially (Peres-Neto et al. 2006). Although the further concern about the effect of unmeasured and

435 spatially structured factors is needed, these results might support previous findings indicating the

436 importance of source-sink effects not only in the population dynamics of individual species but

437 also in the assemblage determination of stream fishes (Falke \& Fausch 2010). Source-sink

438 dynamics are an aspect of metacommunity dynamics, in which dispersal from a large source

439 population of component species maintains small sink populations in neighbouring local

440 communities that cannot be maintained by self-reproduction and would become extinct without

441 immigration from other local communities (Amarasekare 2003). Dispersal of individuals from a

442 source population maintains a sink population of a species, which helps to increase the local

443 richness and diversity of species (Amarasekare 2003; Holyoak et al. 2005). In the present study

444 area, no artificial structures were present that strongly restricted fish dispersal. However, if any

445 artificial barriers, such as a sediment control dam without a fishway, are constructed and restrict 
446 the free movement of fish, sink populations may become extinct (Jager et al. 2001), and the

447 richness and diversity of local fish assemblages may decrease (Stewart et al. 2001). My results

448 re-emphasize the importance of river connectivity in maintaining the species diversity of fishes,

449 which is a crucial issue for stream fish conservation (Nilsson et al. 2005).

450 Independently and along with the spatial predictors, the environmental predictors of

451 elevation and mean current velocity significantly explained the variation in species composition at

452 the medium scale. In addition, the local density of several fish species was significantly correlated

453 with mean current velocity within a reach. This variable changed within a spatial extent of $<10 \mathrm{~km}$.

454 Within this spatial range, the distance decay in species composition was not steep. Previous studies

455 on single fish species showed that fish select a reach with a favourite current velocity within a

456 scale for which the migration of individuals is not prevented (Table 1). The effect of habitat

457 selection along environmental gradients on assemblage structuring may be strong at the $<10-\mathrm{km}$

458 scale; thus, a shifting point of the rank of the relative importance of environmental and spatial

459 factors may exist within the medium scale (400-40,000 m).

460

461 2. Fine scale

462 At the fine spatial scale, contrary to my prediction, the variation in species composition was

463 significantly associated with spatial predictors at all sampling sites, with the exception of site 14 
464 but was not simply explained by the distance. In contrast, environmental predictors explained a

465 relatively small portion of the total variation in species composition, although the environmental

466 factors significantly affected species composition at several sites at the fine scale.

467 In the situation where an environmental factor at medium or large spatial scales strongly

468 constrains the ecological traits of stream fishes, the contribution of environmental factors may be

469 small because of decreased interspecific variation in habitat selectivity (Grossman et al. 2010). In

470 general, environmental harshness seems to be stronger in the upper reaches than in the lower

471 reaches (Grossman et al. 2010), so it is predictable that the contribution of environmental factors

472 will be small in the upper reaches and large in the lower reaches. However, the fraction explained

473 by environmental variables was not large in the lower reaches, but it was large at 2 sites in the

474 upper reaches (Table 3). In addition, a previous study reported the interspecific variation in habitat

475 use of the dominant fish species in the upper middle reaches of the research area (Nakagawa et al.

476 2012). Therefore, the effect of an environmental factor probably does not explain the small

477 contribution of environmental factors in the assemblage structuring of stream fishes at the fine

478 scale.

479 To simultaneously explain both the large contribution of spatial factors and weak habitat

480 selectivity, a dispersal process at the fine spatial scale may need to be considered. This process

481 may be associated with the home range of individuals. Several significant environmental features 
482 (deep pool, cobbles, crevice of bedrock and cover) usually function as a refuge or rest site (Table

483 1) and may be used as a core site within the home range of individual fish (usually smaller than a

484 few hundred metres for fish of $<50 \mathrm{~cm}$ standard length; Minns 1995), as shown in studies of

485 stream and marine fishes (Miller \& Geibel 1973; Lowe et al. 2003; Jorgensen et al. 2006;

486 Watanabe 2008). When fish use a particular environmental patch as a core site within their home

487 range, some environmental factors will exhibit relationships with the distribution of that fish

488 species. On the other hand, in situations where fish limit their movement within a fixed area

489 independently of environmental gradients around a core site, some spatial factors would also

490 exhibit relationships with the distribution of that fish species. This situation would also affect

491 species composition because of spatial autocorrelation in individual species density that relates to

492 the core site distribution. Horizontal and patch-like patterns of spatial predictors that are

493 significantly related to fish distribution may corroborate the importance of the home range and

494 associated core sites in structuring fish assemblages.

495

496 Concluding remarks

497 The present study successfully demonstrated that the ordinal rank of the relative importance of

498 environmental and spatial factors changes between 2 spatial scales via alterations of multiple,

499 scale-dependent factors. However, large portions of the variation in species composition could not 
500 be statistically attributed to either environmental or spatial factors. Furthermore, potentially

501 important environmental factors that were not included in the analysis may have resulted in

502 spurious correlations between species composition and spatial factors, such as primary production

503 (Vannote et al. 1980) or interspecific interactions (Hutchinson 1959; MacArthur \& Levins 1967;

504 Amarasekare 2003). In future studies, I hope to strictly evaluate the effect of significant factors

505 using multi-site comparisons (Didham et al. 1998; Brown and Swan 2010) or environmental

506 control experiments (Eggleston and Lipcius 1992; Everett and Ruiz 1993). If the large

507 contributions of spatial factors and distance decay are caused by source-sink dynamics in a river

508 that is fragmented at a scale smaller than $10 \mathrm{~km}$ by natural or artificial structures, the contribution

509 of spatial factors will be smaller than that in a non-fragmented river, and the distance decay of

510 assemblage similarity will be steep at a smaller scale. Furthermore, if the home range of individual

511 fish affects assemblage structuring, the distribution of fishes will be explained by the distance

512 from the home-range core. This prediction may be testable with experiments using artificial

513 removal/placement of microhabitats functioning as home-range cores (e.g. cover or boulders).

514 The implication that fine-scale assemblage structure may be determined by factors that

515 change at a medium or larger spatial scale has an important meaning for the conservation of

516 species diversity in stream ecosystems. When conducting environmental assessments, if a

517 prediction concerning a certain effect is based on data that were only sampled within a planned 
518 construction area (i.e. data that do not include factors changing at a larger spatial scale), the

519 assessment risks bias or misinterpretation (Roth et al. 1996). In the future, knowledge of current

520 community ecology that considers multiple-scale processes will be increasingly essential for

521 management decisions regarding modification or maintenance of stream environments. 


\section{Acknowledgements}

524 I thank Katsutoshi Watanabe of Laboratory of Animal Ecology, Graduate School of Science,

525 Kyoto University, Takehiro Okuda of Fisheries Research Agency, National Research Institute of

526 Fisheries Science, Japan, and Mikio Inoue, Graduate School of Science and Engineering, Ehime

527 University, Takuya Sato, Field Science Education and Research Center, Kyoto University, for

528 numerous useful suggestions. I thank Koji Tominaga for helping field survey, and Michio Hori,

529 Teiji Sota and other members of Laboratory of Animal Ecology, Graduate School of Science,

530 Kyoto University for many helpful comments. I thank the staffs of Ashiu Forest Research Station,

531 Field Science Education and Research Center of Kyoto University, and the staff of Miyama

532 Gyokyo (Fisheries Cooperative of Miyama, Yura River), Kyoto, Japan. This study was supported

533 by Global COE Program A06 'Formation of a Strategic Base for Biodiversity and Evolutionary

534 Research: from Genome to Ecosystem’ from the Ministry of Education, Culture, Sports and

535 Technology, Japan.

536

\section{$537 \quad$ Literature cited}

538 Amarasekare, P. 2003. Competitive coexistence in spatially structured environments: a synthesis.

$539 \quad$ Ecology Letters 6: 1109-1122.

540 Beisner, B. E., Peres, P. R., Lindström, E. S., Barnett, A. \& Longhi, M. L. 2006. The role of 
environmental and spatial processes in structuring lake communities from bacteria to fish.

542 Ecology 87: 2985-2991.

543 Blanchet, F. G., Legendre, P. \& Borcard, D. 2008. Forward selection of explanatory variables.

$544 \quad$ Ecology 89: 2623-2632.

545 Borcard, D., Legendre, P. \& Drepeau, P. 1992. Partialling out the spatial component of ecological variation. Ecology 73: 1045-1055.

547 Borcard, D. \& Legendre, P. 2002. All-scale spatial analysis of ecological data by means of 548 principal coordinates of neighbor matrices. Ecological Modelling 153: 51-68.

549 Borcard, D., Legendre, P., Avois-Jacquet, C. \& Tuomisto, H. 2004. Dissecting the spatial structure 550 of ecological data at multiple scales. Ecology 85: 1826-1832.

551 Brown, B. L. \& Swan, C. M. 2010. Dendritic network structure constrains metacommunity 552 properties in riverine ecosystems. Journal of Animal Ecology 79: 571-580.

553 Cottenie, K. 2005. Integrating environmental and spatial processes in ecological community dynamics. Ecology Letters 8: 1175-1182. responses to tropical forest fragmentation. Ecological Monograph 68: 295-323. principal coordinate analysis of neighbor matrices (PCNM). Ecological Modeling 196: 
559 483-493.

560 Dray, S. 2010. Moran’s eigenvectors of spatial weighting matrices in R. In: S. Dray, Legendre, P.

561 \& Peres-Neto, P. R. 2006. appendix of spatial modeling: a comprehensive framework for

562 principal coordinate analysis of neighbor matrices (PCNM). Ecological Modeling 196:

563 483-493.

564 Durance, I. Lepichon, C. \& Ormerod, S. J. 2006. Recognizing the importance of scale in the 565 ecology and management of riverrine fish. River Research and Applications 22: 1143-1152.

566 Eggleston, D. B. \& Lipcius, R. N. 1992. Shelter selection by spiny lobster under variable predation risk, social conditions, and shelter size. Ecology 73: 992-1011.

568

Elliott, J. M. 1981. Some aspects of thermal stress of freshwater teleosts. In: Pickering, A. D., ed. Stress and Fish. London: Academic Press, pp. 209-245.

570 Erős, T., Heino, J., Schmera, D. \& Rask, M. 2009. Characterising functional trait diversity and trait-environment relationships in fish assemblages of boreal lakes. Freshwater Biology

572 54:1788-1803.

573 Erős, T., Sály, P., Takács, P., Specziar, A. \& Bíró, P. 2012. Temporal variability in the spatial and 574 environmental determinants of functional metacommunity organization - stream fish in a 575 human modified landscape. Freshwater Biology 57:1914-1928.

576 Everett, R. A. \& Ruiz, G. M. 1993. Coarse woody debris as a refuge from predation in aquatic 

communities. Oecologia 93: 475-486.

578 Falke, J. A. \& Fausch, K. D. 2010. From metapopulations to metacommunities: linking theory

579 with empirical observations of the spatial population dynamics of stream fishes. In: Gido, K.

580 B. \& Jackson, D. A., eds. Community ecology of stream fishes: concepts, approaches, and 581 techniques. Bethesda: American Fisheries Society, pp. 207-235.

582 Fausch, K. D., Hawkes, C. L. \& Persons, M. G. 1988. Models that predict standing crop of stream 583 fish from habitat variables: 1985-85. United States of Agriculture Forest Service Pacific Northwest Research Station General Technical Report PNW-GTR-213.

Fausch, K. D., Nakano, S. \& Ishigaki, K. 1994. Distribution of Two congeneric charrs in streams of Hokkaido Island, Japan: considering multiple factors across scales. Acta Oecologia 100: $1-12$.

Fausch, K. D., Nakano, S. \& Kitano, S. 1997. Experimentally induced foraging mode shift by sympatric charrs in a Japanese mountain stream. Behavioral Ecology 8: 414-420. stream habitat classification: viewing streams in a watershed context. Environmental Management 10: 199-214.

Fuselier, L., \& Edds, D. 1995. An artificial riffle as restored habitat for threatened Noesho madtom. 
595 Gilbert, B. \& Bennett, J. R. 2010. Partitioning variation in ecological communities: do the

596 numbers add up? Journal of Appried Ecology 47: 1071-1082.

597 Grossmann, G. D., Ratajczak Jr, R. E., Farr, M. D., Wagner, C. M. \& Petty, J. T. 2010. Why there

598 are fewer fish upstream. In: Gido, K. B. \& Jackson, D. A., eds. Community ecology of stream fishes: concepts, approaches, and techniques. Bethesda: American Fisheries Society,

600 pp. 63-81.

601

Heino, J. 2011. A macroecological perspective of diversity patterns in the freshwater realm.

602 Freshwater Biology 56: 1703-1722.

603

Hill, J. \& Grossman, G. D. 1993. An energetic model of microhabitat use for rainbow trout and

604 rosyside dace. Ecology 74: 685-698.

605

Hill, W. R., Mulholland, P. J. \& Marzolf, E. R. 2001. Stream ecosystem responses to forest leaf

606 emergence in spring. Ecology 82: 2306-2319.

607

Hoeinghaus, D.J., Winemiller, K.O. \& Birnbaum, J.S. 2007. Local and regional determinants of

608 stream fish assemblage structure: inferences based on taxonomic vs. functional groups.

609 Journal of Biogeography 34:324-338.

610 Holyoak, M., Leibold, M. A. Monquet, N. M., Holt, R. D. \& Hoops, M. S. 2005.

611 Metacommunities: a framework for medium scale community ecology. In: Holyoak, M., Leibold, M. A. \& Holt, R. D., eds. Metacommunities: spatial dynamics and ecological 

communities. Chicago: The University of Chicago Press, pp. 1-31.

614 Hutchinson, G. E. 1959. Homage to Santa Rosalia or why are there so many kind of animals. American Naturalist 93: 145-159.

616 Inoue, M., Nakano, N. \& Nakayama, F. 1997. Juvenile masu salmon (Oncorhynchus masou) abundance and stream habitat relationships in northern Japan. Canadian Journal of Fisheries and Aquatic Sciences 54: 1331-1341. fragmentation by dams and its effects on white sturgeon populations. Environmental Biology of Fishes 60: 347-361.

622

Jorgensen, S. J., Kaplan, D. M., Klimley, A. P., Morgan, S. G., O’Farrell, M. R. \& Botsford, L. W. 2006. Limited movement in blue rockfish Sebastes mystinus: internal structure of home range. Marine Ecology Progress Series 327: 157-170.

625 Karst, J., Gilbert, B. \& Lechowicz. M. J. 2005. Fern community assembly: the roles of chance and the environment at local and intermediate scales. Ecology 86: 2473-2486.

627 Kautza, A. \& Sullivan, M.P. 2012. Relative effects of local-and landscape-scale environmental factors on stream fish assemblages: evidence from Idaho and Ohio, USA. Fundamental and Applied Limnology 180: 259-270. 
Nelson, J. S., eds. Cyprinid fishes: systematics, biology and exploitation. London: Chapman

632 \& Hall, pp. 353-377.

633 Legendre, P. \& Legendre, L. F. J. 1998. Numerical ecology, second English edition. Elsevier,

634 Amsterdam, pp. 853.

635

Legendre, P. \& Gallagher, E. D. 2001. Ecological meaningful transformation for ordination of

636 species data. Acta Oecologia 129: 271-280.

Leibold, M. A., Holyoak, M., Mouquet, N., Amarasekare, P., Chase, J. M., Hoopes, M. F., Holt, R. D., Shurin, J. B., Law, R., Tilman, D., Loreau, M., \& Gonzalez, A. 2004. The

640 metacommunity concept: a framework for multi-scale community ecology. Ecology Letters

641

Leps, J., \& Smilauer, P. 2003. Multivariate analysis of ecological data using CANOCO. New York:

642 Cambridge University Press, 267 pp.

643

Lowe, C. G., Topping, D. T., Cartamil, D. P., Papastamatiou, Y. P. 2003. Movement patterns, home

644 range, and habitat utilization of adult kelp bass Paralabrax clathratus in a temperate no-take marine reserve. Marine Ecology Progress Series 256: 205-216.

646 MacArthur, R. H. 1958. Population ecology of some warblers of northeastern coniferous forests.

647 Ecology 39: 599-619. 
649

coexisting species. American Naturalist 101: 377-385.

650

Magalhães, M.F., Batalha, D.C., Collares-Pereira, M.J. 2002. Gradients in stream fish assemblages

651 across a Mediterranean landscape: contributions of environmental factors and spatial

652 structure. Freshwater Biology 47:1015-1031.

653

Matthews, W. J. 1998. Patterns in freshwater fish ecology. Norwell: Kluwer Academic Publishers,

654 756 pp.

655

McGarvey, D. J. \& Ward, G. M. 2008. Scale dependence in the species-discharge relationship for

656 fishes of the southeastern U.S.A.. Freshwater Biology 53: 2206-2219.

657

Miller, D. J. \& Geibel, J. J. 1973. Summary of blue rockfish and lingcod life histories, a reef

658 ecology study; and giant kelp, Macrocystis pyrifera, experiments in Monterey Bay,

659 California. California: State of California, Resources Agency, Department of Fish and Game,

660 137 pp.

661

Mills, C. A. 1991. Reproduction and life history. In: Winfield, I. J. \& Nelson, J. S., eds. Cyprinid

662 fishes: systematics, biology and exploitation. London: Chapman \& Hall, pp. 483-508. Fisheries and Aquatic Science 52: 1499-1508. basis. Geological Society of America Bulletin 109: 596-611. 
667 Muneepeerakul, R., Bertuzzo, E., Lynch, H. J., Fagan, W. F., Rinaldo, A. \& Rodriguez-Iturbe, L.

668 2008. Neutral metacommunity models predict fish diversity patterns in Mississippi-Missouri

669 basin. Nature 453: 220-223.

670

Mykrä, H., Heino, J. \& Muotka, T. 2007. Scale-related patterns in the spatial and environmental components of stream macroinvertebrate assemblage variation. Global Ecology and

672 Biogeography 16: 149-159.

673 Nakagawa, H., Yamane, H., Yasugi, M., Fujita, T., Yokoi, K., Ashiwa, H., Kitada, N., Takano, H.,

674 Suzuki, N., Kishimoto, J., Maeda, H., Yamano, H., Ito, T., Maruyama, H., Tominaga, K., 675 Hatakeyama, E., Goto, M. \& Takahashi, D. 2012. Diel changes in resource use and diet 676 overlap in temperate stream fishes. Ecological Research 27: 417-426.

Nakamura, M. 1969. Cyprinidae in Japan (in Japanese). Tokyo: Research Institute for Natural

678 Resources, 455 pp.

679

Nakano, S. 1995. Individual differences in resource use, growth and emigration under the

680 influence of a dominance hierarchy in fluvial red-spotted masu salmon in a natural habitat. Journal of Animal Ecology 64: 75-84. Infrastructure, Transport and Tourism. 
spatio-temporal limitations in nest resources. Environmental Biology of Fishes 62: 393-400.

686 Nilsson, C., Reidy C. A., Dynesius, M. \& Revenga, C. 2005. Fragmentation and flow regulation of the world's large river systems. Science 308: 405-408.

688

Oksanen, J., Kindt, R., Legendre, P., O’Hara, B., Simpson, G. L. \& Stevens, M. H. H. 2008. vegan:

689 community ecology package, version 1.17-6. http://cran.r-project.org/.

690

Okuda, T., Noda, T, Yamamoto, T., Hori, M. \& Nakaoka, M. Contribution of environmental and spatial processes to rocky intertidal metacommunity structure. Acta Oecologia 36: 413-422.

692

Peres-Neto, P. R., Legendre, P., Dray, S. \& Borcard, D. 2006. Variation partitioning of species data matrices: estimation and comparison of fractions. Ecology 87: 2614-2625.

694

Perkin, J. S. \& Gido, K. B. 2011. Stream fragmentation thresholds for a reproductive guild of great plains fishes. Fisheries 36: 371-383.

696

Pianka, E. R. 1966. Latitudinal gradients in species diversity: a review of concepts. American

697 Naturalist 100: 33-46.

698

Power, M.E. 1984. Depth distributions of armored catfish: predator induced resource avoidance?

699 Ecology 65: 523-528.

700

Quist, M. C., Hubert, W. A. \& Isaak, D. J. 2004. Fish assemblage structure and relations with 
703 R-Development-Core-Team. 2008. R: a language and environment for statistical computing, Ver. 2.11.1. R Foundation for Statistical Computing, Vienna, Austria. http://cran.r-project.org/.

705 Roth, N. E., Allan, J. D. \& Erickson, D. L. 1996. Landscape influence on stream biotic integrity 706 assessed at multiple spatial scales. Landscape Ecology 11: 141-156.

707

Sály, P., Takács, P., Kiss, I., Bíró, P. \& Erős, T. 2011. The relative influence of spatial context and catchment- and site-scale environmental factors on stream fish assemblages in a human modified landscape. Ecology of Freshwater Fish 20: 251-262.

Sechnick, C. W., Carline, R. F., Stein, R. A. \& Rankin, E. T. 1986. Habitat selection by smallmouth bass in response to physical characteristics of a simulated stream. Transaction of American Fisheries Society 115: 314-321.

713 Shirvell, C. S. 1990. Role of instream rootwads as juvenile coho salmon (Onchorhynchus Kisutch)

714 and steelhead trout (O. mykiss) cover habitat under varying streamflows. Canadian Journal

$715 \quad$ of Fisheries and Aquatic Science 47: 852-861.

716 Smith, T. W. \& Lundholm, J. T. 2010. Variation partitioning as a tool to distinguish between niche and neutral processes. Ecography 33: 648-655.

718 Southwood, T. R. E. 1977. Habitat templet for ecological strategies? Journal of Animal Ecology 46: 337-365. 
721

722

723

724

725

726

727

728

729

730

731

732

733

734

735

736

737

738

watershed, riparian-corridor, and reach-scale characteristics on aquatic biota in agricultural watersheds. Journal of the American water resources association 37: 1475-1487.

Stewart-Koster, B., Kennard, M.J., Harch, B.D., Sheldon, F., Arthington, A.H., Bradley J. Pusey, B.J. 2007. Partitioning the variation in stream fish assemblages within a spatio-temporal hierarchy. Marine and Freshwater Research 58: 675-686.

Tamada, K. 2010. River bed features affect the riverine distribution of two amphidromous Rhinogobius species. Ecology of Freshwater Fish 20: 23-32.

Townsend, C. R. \& Hildrew, A. G. 1994. Species traits in relation to a habitat templet for river systems. Freshwater Biology 31: 265-275.

Vannote, R. L., Minshall, G. W., Cummins, K, W., Sedell, J. R. \& Cushing, C. E. 1980. The river continuum concept. Canadian Journal of Fisheries and Aquatic Sciences 37: 130-137.

Wang, L., Lyons, J., Rasmussen, P., Seelbach, P., Simon, T.,Wiley, M., Kanehl, P., Baker, E., Niemela, S., Stewart, P.M. 2003. Watershed, reach, and riparian influences on stream fish assemblages in the Northern Lakes and Forest Ecoregion, U.S.A. Canadian Journal of Fisheries and Aquatic Sciences 60:491-505.

Watanabe, K. 1994. A note on the reproductive ecology of the torrent catfish, Liobagrus reini (Siluriformes: Amblycipitidae). Japan. Journal of Ichthyology 41:219-221.

Watanabe, K. 2008. Diel activity and reproductive territory of the Japanese bagrid catfish, 
739 Pseudobagrus ichikawai. Environmental Biology of Fishes 81: 77-86.

740 Wentworth, C. K. 1922. A Scale of Grade \& Class Terms for Clastic Sediments. The Journal of

$741 \quad$ Geology 30: 377-392.

742 Winemiller, K.O., Flecker, A. S. \& Hoeinghaus, D. J. 2010. Patch dynamics and environmental

743 heterogeneity in lotic ecosystems. Journal of American Benthological Society 29: 84-99

744 Yamane, H., Yokoyama, T., Nagata, H. \& Yamada, T. 2004. Reproductive ecology and life history

745 of the bagrid catfish, Pseudobagurus nudiceps (in Japanese). Japanese Journal of

$746 \quad$ Ichthyology 51: 135-147. 
748 Table 1. Environmental factors measured along the Yura River study site and associated

749 mechanisms that determine community structure

\begin{tabular}{|c|c|c|}
\hline Measured environmental factor & Ecological importance & Spatial scale \\
\hline Water temperature & Thermal tolerance (e.g. Elliott 1981, Fausch et al. 1994) & Medium scale \\
\hline Gradient of riverbed & $\begin{array}{l}\text { A determinant factor of river morphology (e.g. Montgomery and } \\
\text { Buffington 1997, Quist et al. 2004) }\end{array}$ & Medium scale \\
\hline Flow rate & A determinant factor of river morphology (e.g. Buffington et al. 2003) & Medium scale \\
\hline Mean width of river channel & $\begin{array}{l}\text { An indicator of the canopy cover which affects primary production in } \\
\text { a river (e.g. Hill et al. 2001) }\end{array}$ & Medium scale \\
\hline Mean water depth of a research site & $\begin{array}{l}\text { An indicator of the frequency of refuges for predators (e.g. Power } \\
\text { 1984) }\end{array}$ & Medium scale \\
\hline $\begin{array}{l}\text { Mean current velocity of a research } \\
\text { site }\end{array}$ & $\begin{array}{l}\text { An indicator of the frequency of a lentic habitat (such as pools) which } \\
\text { are used for foraging or resting (review in Fausch et al. 1988; e.g. } \\
\text { Quist et al. 2004) } \\
\text { A determinant factor of density of reproductive nests (e.g. } \\
\text { Natsumeda 2001) }\end{array}$ & Medium scale \\
\hline $\begin{array}{l}\text { Mean frequency of each substrate } \\
\text { type in a research site }\end{array}$ & $\begin{array}{l}\text { An indicator of the frequency of habitat patches for feeding or } \\
\text { spawning (review in Fausch et al. 1988, Mills 1991, Wooton 1998, } \\
\text { e.g, Inoue et al. 1997, Quist et al. 2004) } \\
\text { A determinant factor of the density of feeding site or reproductive } \\
\text { substrate for some Japanese fishes [e.g. sand for Zacco platypus, } \\
\text { Pseudogobio esocinus and Hemibarbus labeo (Nakamura 1969); } \\
\text { gravel for Tribolodon hakonensis (Nakamura 1969); cobbles for } \\
\text { Rhinogobius spp., Tridentiger kuroiwae and Chaenogobius urotaenia } \\
\text { (Kawanabe and Mizuno 1989, Tamada 2010); boulders for } \\
\text { Pseudobagrus nudiceps, Liobagrus reinii and Cottus pollux (Yamane } \\
\text { 2004, Watanabe 1994, Natsumeda 2001, Nakagawa et al. 2012)] }\end{array}$ & Medium scale \\
\hline $\begin{array}{l}\text { Mean cover frequency of a research } \\
\text { site }\end{array}$ & $\begin{array}{l}\text { A determinant factor of the density of feeding sites, shelter and } \\
\text { reproductive substrate (e.g. Shirvell 1990, Inoue et al. 1997) } \\
\text { Reproductive substrate for some Japanese Cyprinids; Squalidus } \\
\text { gracilis, Carassius auratus (Nakamura 1969) }\end{array}$ & Medium scale \\
\hline Water depth at a plot & Refuge of predators (e.g. Power 1984) & Fine scale \\
\hline Current velocity at a plot & $\begin{array}{l}\text { A factor affecting foraging efficiency (e.g. Hill and Grossman 1993, } \\
\text { Nakano 1995) }\end{array}$ & Fine scale \\
\hline $\begin{array}{l}\text { Frequency of each substrate type at } \\
\text { a plot }\end{array}$ & $\begin{array}{l}\text { Feeding site for some benthic feeders (review in Lamments and } \\
\text { Hoogenboezem 1991) } \\
\text { Shelter from predator or high current speed (e.g. Fuselier and Edds } \\
\text { 1995; review in Matthews 1998) } \\
\text { Feeding site or shelter for some Japanese fishes [e.g. sand for } \\
\text { Pseudogobio esocinus, Squalidus gracilis and Hemibarbus } \\
\text { longirostris (Nakamura 1969); Boulders for Pangtungia herzi, } \\
\text { Niwaella delicata, Pseudobagurus nudiceps, Liobagurus reinii and } \\
\text { Cottus pollux (Nakamura 1969, Kawanabe and Mizuno 1989, } \\
\text { Nakagawa et al. 2012)] }\end{array}$ & Fine scale \\
\hline Cover present/absent at a plot & $\begin{array}{l}\text { Shelter from predator or high current speed (e.g. Sechnick et al. } \\
\text { 1986, Shirvell 1990) }\end{array}$ & Fine scale \\
\hline
\end{tabular}


751 Table 2. Portion of variation ( $R^{2}$ adj.) explained by pure environmental variables [EP], pure spatial

752 variables [SP], both environmental and spatial variables [ES], the total of environmental and

753 spatial variables [T] and the residual fraction of variation [R] estimated by variation partitioning

754 (VP), and that explained by each pure environmental variable and pure spatial variable (Moran’s

755 eigenvector, MEV) obtained from partial redundancy analysis (partial RDA) at the medium scale.

\begin{tabular}{lcc}
\hline & $R_{\text {adj. }}^{2}$ & P-Value \\
\hline EP & 0.052 & $<\mathbf{0 . 0 0 1}$ \\
SP & 0.126 & $<\mathbf{0 . 0 0 1}$ \\
ES & 0.682 & $<\mathbf{0 . 0 0 1}$ \\
$T$ & 0.860 & \\
R & 0.140 & \\
\hline Environmental factors & & \\
Elevation & 0.025 & $\mathbf{0 . 0 0 9}$ \\
Water temperature & 0.011 & 0.208 \\
Mean current velocity & 0.020 & $\mathbf{0 . 0 2 4}$ \\
\hline Spatial factors & & \\
MEV1 & 0.042 & $\mathbf{0 . 0 3 4}$ \\
MEV2 & 0.056 & $\mathbf{0 . 0 0 4}$ \\
MEV3 & 0.056 & $\mathbf{0 . 0 0 3}$ \\
MEV4 & 0.015 & 0.517 \\
MEV5 & -0.007 & 1.000 \\
MEV6 & -0.002 & 0.565 \\
\hline
\end{tabular}


757 Table 3. Portion of variation ( $R^{2}$ adj.) explained by pure environmental variables [EP], pure spatial

758 variables [SP], both environmental and spatial variables [ES], the total of environmental and

759 spatial variables [T] and the residual fraction of variation [R] estimated by variation partitioning

760 (VP), and that explained by each pure environmental variable and pure spatial variable (Moran’s

761 eigenvector, MEV) obtained from partial redundancy analysis (partial RDA) at the fine scale.

762 Mean \pm SD in the left column shows the average and standard deviation of [EP], [SP], [ES], [T]

763 and [R] among all sampling sites. Dashes (-) represent unselected variables by forward selection.

764 MEVs that were not selected at any sampling sites were omitted. Bold values represent significant

765 effects $(P<0.05)$ with $\left(^{* *}\right)$ and without $(*)$ Bonferroni adjustment for species composition by a

766 permutation test. 


\section{Figure legends}

769 Fig. 1. Locations of (a) the Yura River, (b) research area and (c) sampling sites. (d) Arrangement of

770 transects and plots.

771

772 Fig. 2. Longitudinal distribution pattern of fishes. (a) Fishes mainly distributed in the upper area.

773 (b) Fishes mainly distributed in the upper-middle area. (c) Fishes mainly distributed in the

774 lower-middle area. (d) Fishes mainly distributed in the lower area. Some rare species are omitted

775 for simplicity. The number of observed individuals was adjusted to a maximum of 1 by dividing

776 the maximum number of observed individuals among the sampling sites for each fish species.

777

778 Fig. 3. Distance-similarity relationships in species composition and habitat environment at the

779 medium and fine spatial scales. In each figure, values represent the similarity of a given pair of

780 sites (medium scale) or plots (fine scale). The displayed curve is a running median with a sampling

781 proportion of 0.5 . At the fine scale, similarities between $<5 \mathrm{~m}$ and $>50 \mathrm{~m}$ distant plots were

782 eliminated from the analysis because they did not exist in common at all sampling sites.

783

784 Fig. 4. Ordinations of Moran's eigenvectors (MEVs) 1, 2 and 3 along the river course that were

785 significantly correlated with the distribution pattern of fishes at the medium scale, obtained for a 
786 spatial weighting matrix calculated using the approximate spatial structure of the arrangement of

787 sampling sites.

788

789 Fig. 5. Mappings of Moran’s eigenvectors (MEVs) 2, 4 and 45 along the river course that were

790 significantly correlated with the distribution pattern of fishes at the fine scale, obtained for a

791 spatial weighting matrix calculated using the approximate spatial structure of the arrangement of

792 sampling plots at sites 5-13 and 15-19.

793 
Figure 1 (Nakagawa, H)

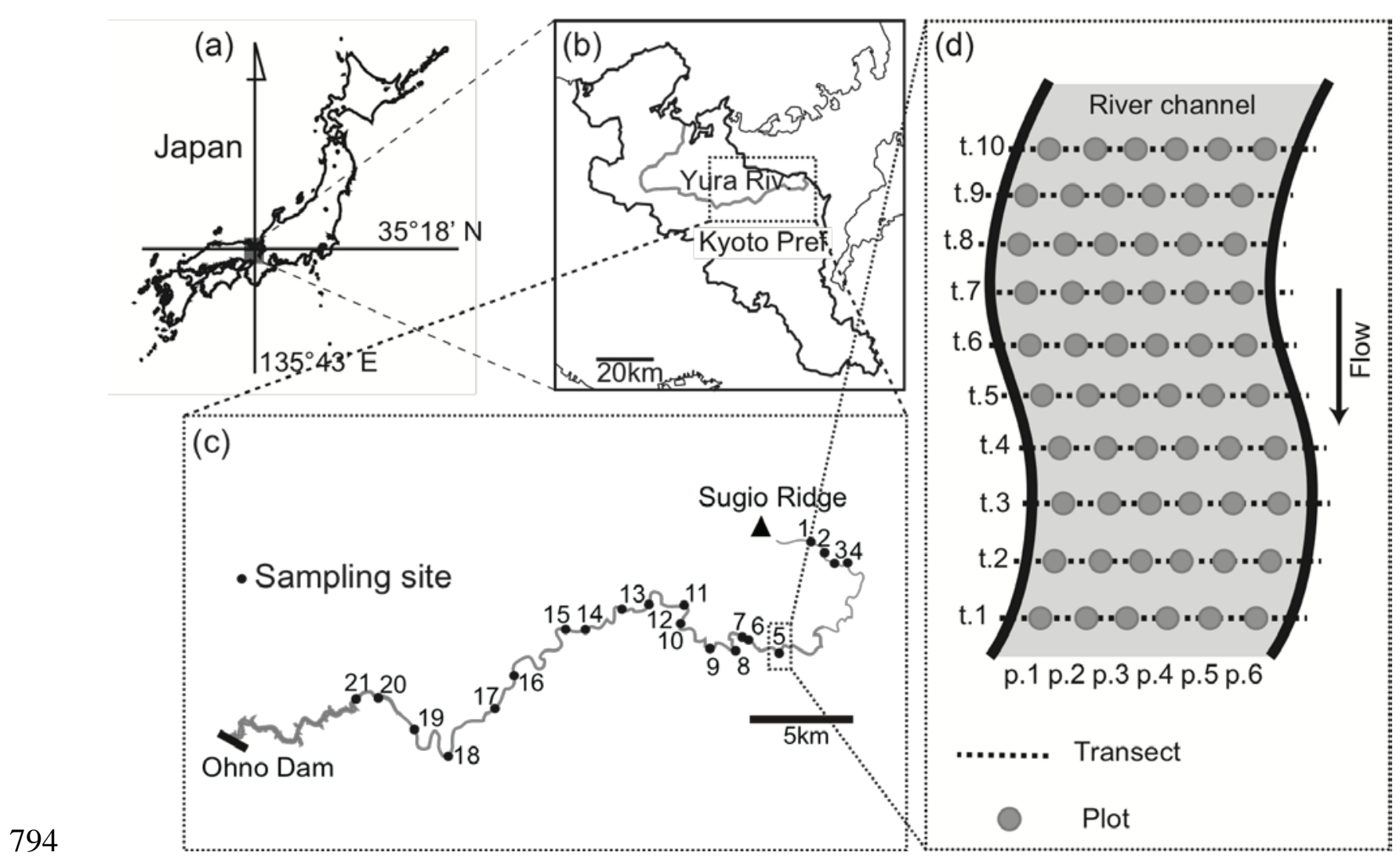


Figure 2 (Nakagawa, H)

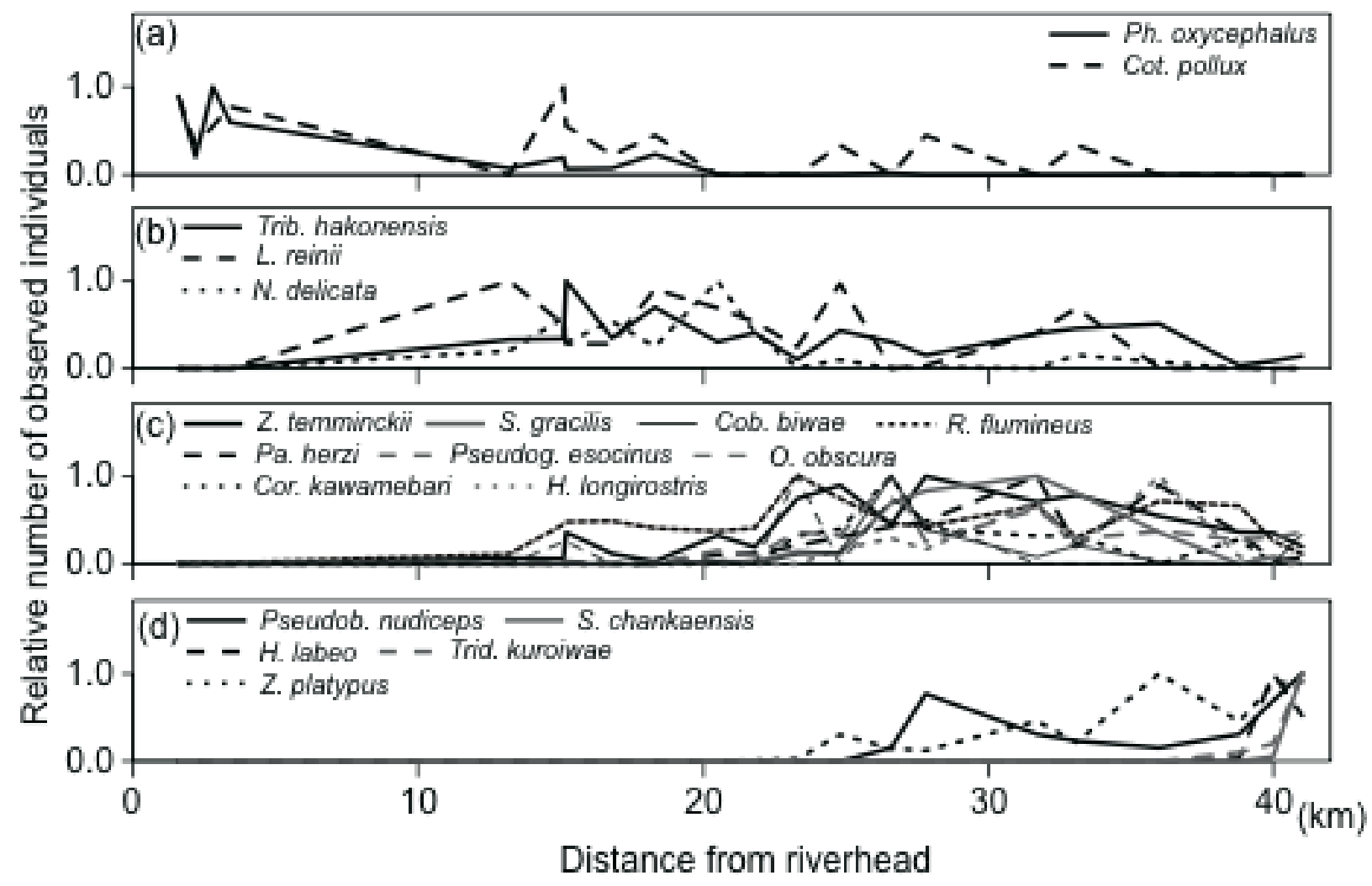


Figure 3 (Nakagawa, H)



(b) Species composition (fine scale)

(c) Environments (medium scale)

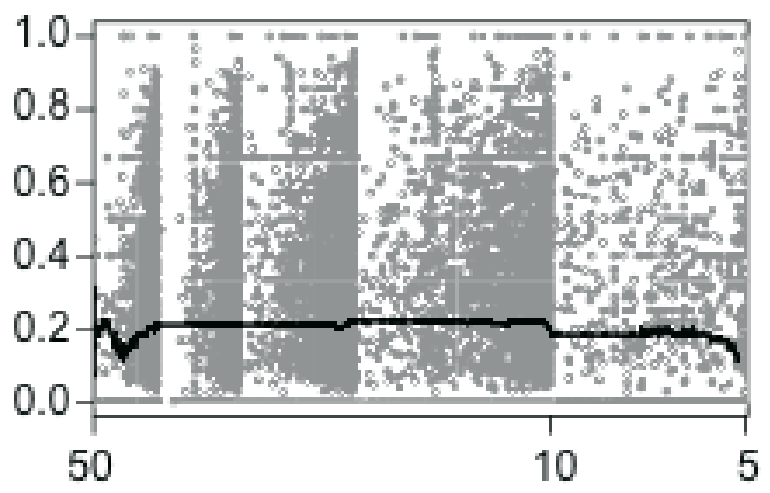

(d) Environments (fine scale)

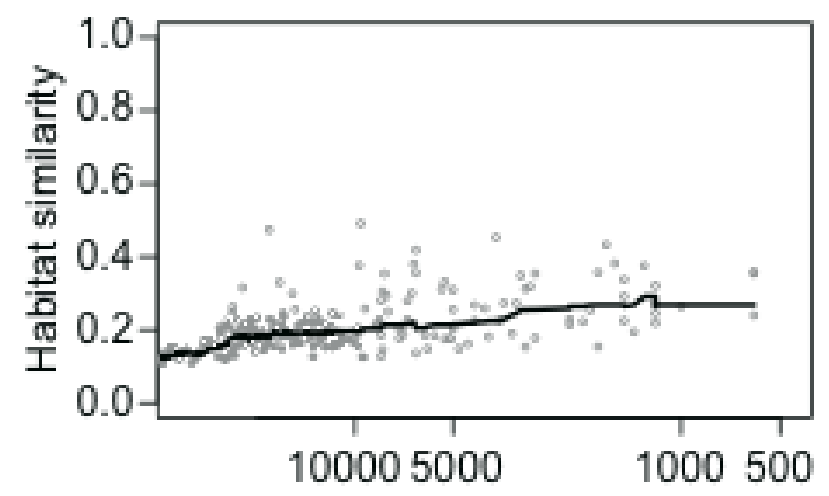
$\log$ (distance between sites; m)

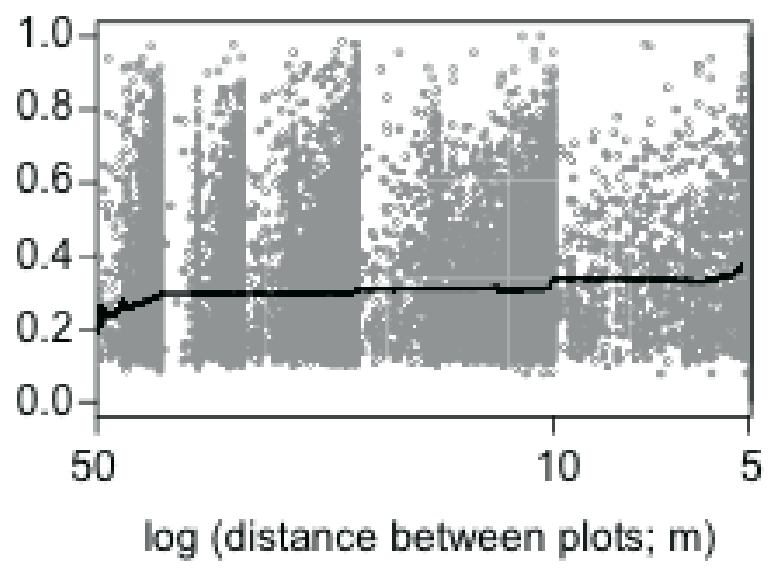


Figure 4 (Nakagawa, H)
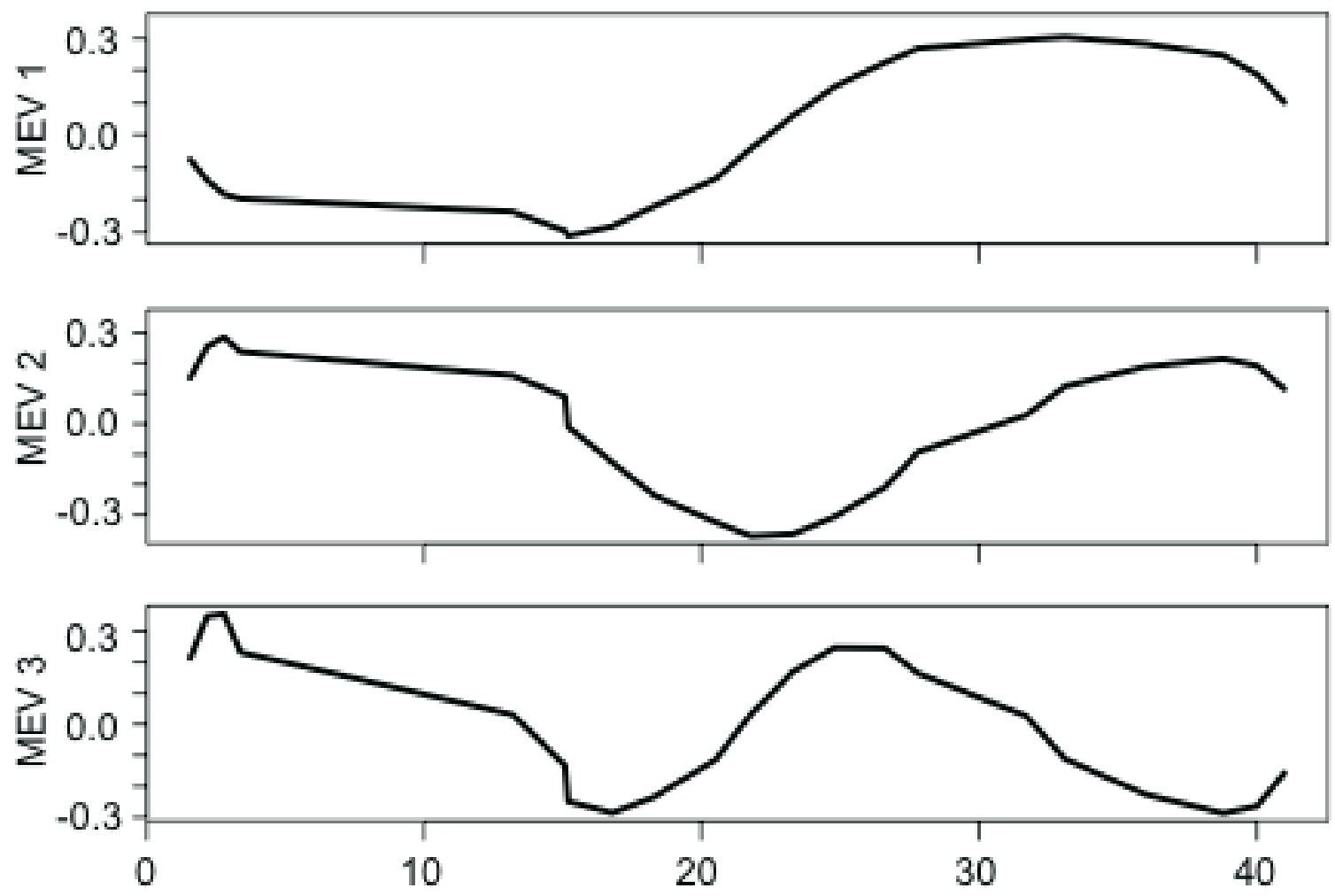

Distance from riverhead $(\mathrm{km})$ 
Figure 5 (Nakagawa, H)

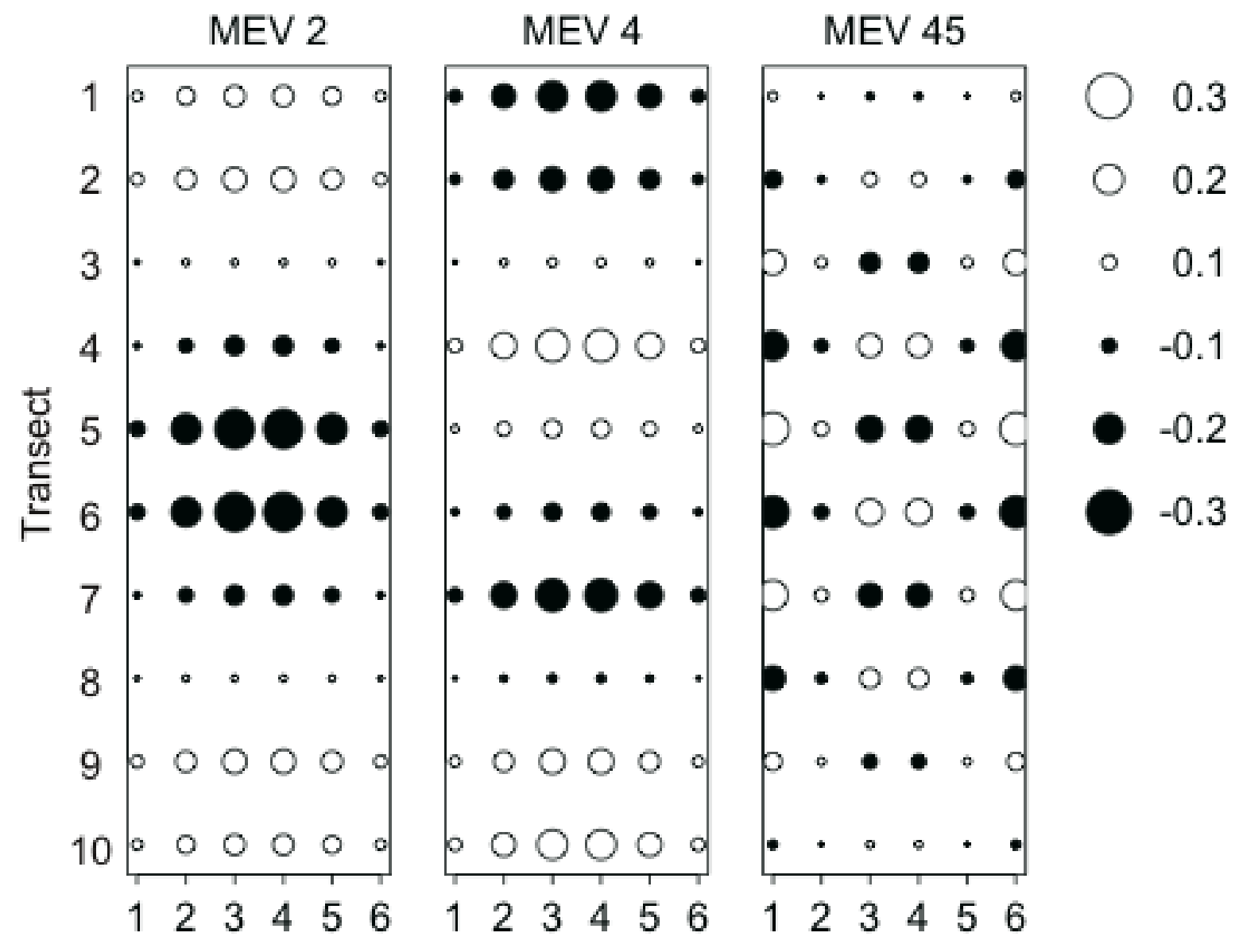

Plot 
(a) Medium scale



(b) Fine scale

5-m interval transect and 4 plots Plot

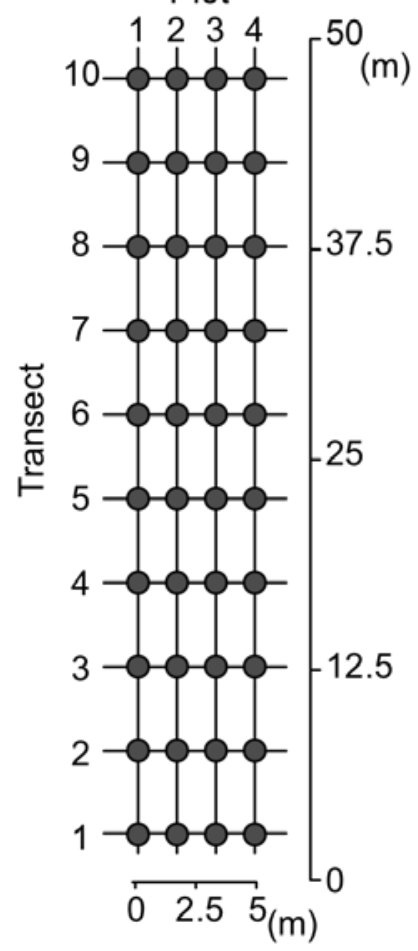

10-m interval transect and 6 plots

20-m interval transect and 8 plots Plot

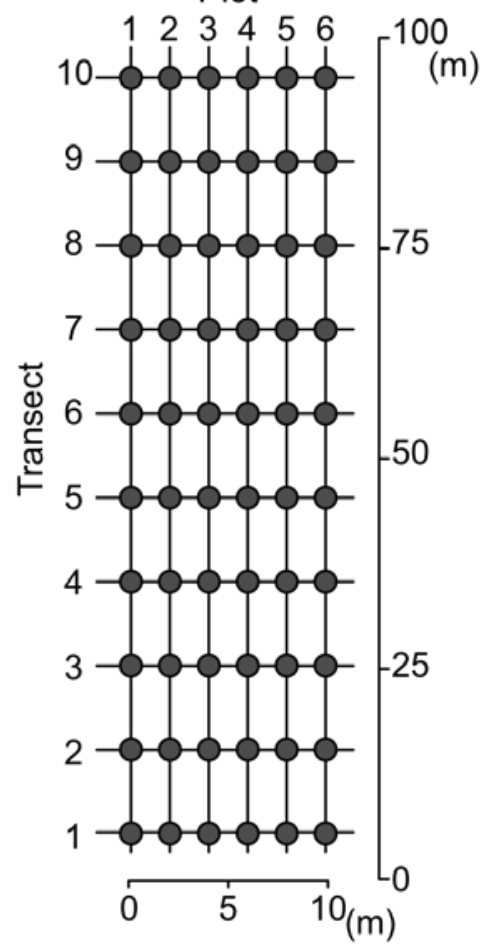

Plot

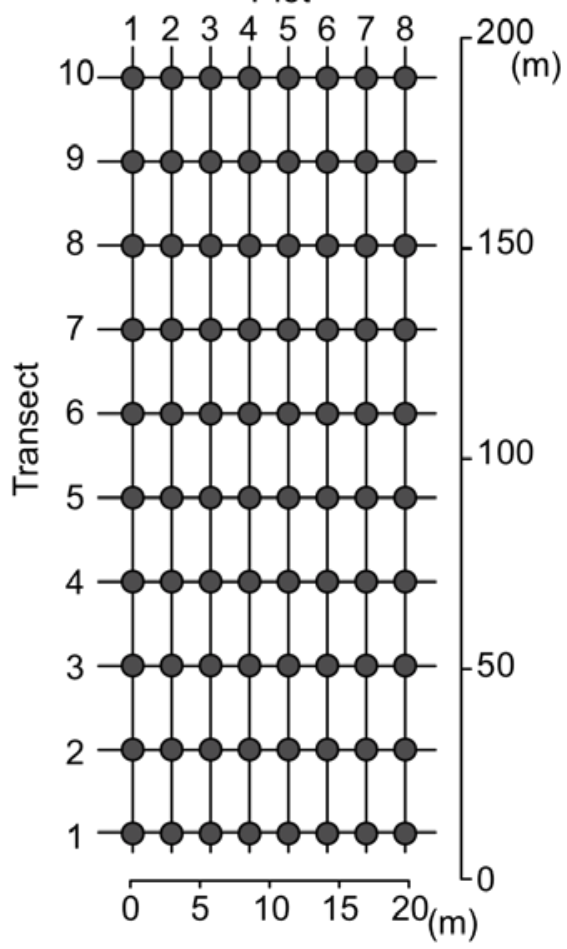

Appendix 1. Approximated spatial structure of the community and arrangement of sampling sites

\section{2}

803

and plots. (a) The spatial structure at the medium scale that approximated a 1-dimensional

804

structure. (b) The spatial structure at the fine scale that approximated a grid structure (see Materials and methods for details). 


\section{Appendix 2}

807 Appendix 2. Observed number of individuals of each fish species at each sampling site.

\begin{tabular}{|c|c|c|c|c|c|c|c|c|c|c|c|c|c|c|c|c|c|c|c|c|c|c|c|c|}
\hline Species \Site & 1 & 2 & 3 & 4 & 5 & 6 & 7 & 8 & 9 & 10 & 11 & 12 & 13 & 14 & 15 & 16 & 17 & 18 & 19 & 20 & 21 & day & night & Total \\
\hline Oncorhynchus masou & 2 & 2 & 4 & 1 & 3 & 0 & 0 & 1 & 9 & 0 & 2 & 0 & 0 & 0 & 0 & 0 & 0 & 0 & 0 & 0 & 0 & 12 & 12 & 24 \\
\hline Cottus & 8 & 3 & 5 &  & 0 & 9 & 5 & 2 & 4 & 0 & 0 & 0 & . & . & 4 & 0 & 3 & 0 & 0 & 0 & & 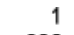 & & 53 \\
\hline hoxinu & 157 & 36 & 177 & 106 & 13 & 34 & 12 & 13 & 41 & 1 & 0 & 0 & 1 & 4 & 0 & 0 & 0 & 1 & 0 & 0 & & 336 & 30 & 596 \\
\hline$a b c$ & 0 & 0 & 0 & 0 & 32 & 16 & 0 & & 29 & 22 & 17 & 8 & 31 & 0 & 1 & 13 & 22 & & c & & & 5 & 04 & 09 \\
\hline ata & c & 0 & 0 & 0 & 25 & 72 & 37 & 67 & 31 & 124 & 51 & 1 & 12 & 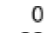 & 2 & 0 & 19 & $g$ & 0 & 0 & & 359 & 91 & 150 \\
\hline onensis & 0 & 0 & 0 & 0 & 39 & 40 & 118 & 41 & 82 & 36 & 48 & 12 & 51 & 36 & 18 & 47 & 54 & 60 & 4 & 10 & 1 & 592 & 121 & 713 \\
\hline ckii & 0 & 0 & 0 & 0 & 11 & 10 & 62 & 20 & 5 & 56 & 33 & 128 & 154 & 78 & 172 & 122 & 135 & 94 & 63 & 61 & $x^{2}$ & 564 & 674 & 1238 \\
\hline mineus & 0 & 0 & 0 & 0 & 40 & 178 & 189 & 193 & 161 & 147 & 161 & 405 & 297 & 183 & 170 & 263 & 118 & 285 & 263 & 100 & 40 & 017 & 176 & 3193 \\
\hline ura & 0 & 0 & 0 & 0 & 0 & 1 & 1 & 0 & 0 & 0 & 0 & 4 & 0 & 3 & 2 & 0 & 0 & 0 & 0 & 0 & 0 & 3 & & 11 \\
\hline Itivelis ${ }^{\circ}$ & 0 & 0 & 0 & 0 & 1 & 0 & 1 & 0 & 4 & 9 & 16 & 3 & 3 & 8 & 5 & 23 & 10 & 7 & 0 & 1 & 1 & 77 & 15 & 92 \\
\hline$z l$ & 0 & 0 & 0 & 0 & 1 & 1 & 2 & 0 & 0 & 7 & 8 & 14 & 21 & 29 & 33 & 68 & 14 & 61 & 24 & 3 & & 151 & 1 & 291 \\
\hline girostris & 0 & 0 & 0 & 0 & 0 & 0 & 0 & 0 & 0 & 1 & 0 & 0 & 4 & 7 & 4 & 17 & 4 & 24 & 2 & 0 & & 13 & 50 & 63 \\
\hline$M S$ & 0 & 0 & 0 & 0 & 0 & 0 & 0 & & 0 & 1 & 1 & 5 & 4 & 25 & 30 & 36 & 9 & 13 & 0 & 3 & & 6 & 61 & 147 \\
\hline socinus & 0 & 0 & 0 & 0 & 0 & 0 & 1 & 0 & 0 & 12 & 7 & 29 & 26 & 80 & 20 & 50 & 23 & 30 & 22 & 24 & 29 & 48 & o & 353 \\
\hline $\operatorname{acc}$ & 0 & 0 & 0 & 0 & 0 & 0 & 2 & & 0 & 2 & 5 & 11 & 119 & 56 & 48 & 179 & 85 & 392 & 177 & 347 & 355 & 207 & 57 & 1781 \\
\hline awamebai & 0 & 0 & 0 & 0 & 0 & 0 & 0 & & & 0 & 0 & 8 & 10 & 2 & 1 & 8 & 8 & 0 & 7 & 0 & & 3 & & 78 \\
\hline , ODI & 0 & 0 & 0 & 0 & 0 & 0 & 0 & & & 1 & 0 & 4 & 5 & 3 & 1 & 3 & 8 & & 0 & 0 & & 43 & & 38 \\
\hline nudiceps & 0 & 0 & 0 & 0 & 0 & 0 & 0 & & & 0 & & & 0 & & 10 & 4 & 3 & 2 & 4 & 9 & & 4 & 43 & 47 \\
\hline em & 0 & 0 & 0 & 0 & 0 & 0 & 0 & 0 & 0 & 0 & 0 & 0 & 0 & & 0 & 0 & 0 & 0 & 1 & 27 & 14 & 37 & & 42 \\
\hline ochirus ${ }^{2}$ & 0 & 0 & 0 & 0 & 0 & 0 & 0 & & & 0 & 0 & 0 & 0 & & 0 & 0 & 0 & 0 & 0 & & & 2 & & 2 \\
\hline & 0 & 0 & 0 & & 0 & 0 & 0 & & & & & & & & & 0 & 0 & & & & 1 & 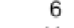 & 13 & 19 \\
\hline & 0 & 0 & 0 & & & 0 & & & & & & & & & & & & & & & 10 & 11 & & 13 \\
\hline enit & 0 & 0 & & & & & & & & & & & & & & & & & & & & & & \\
\hline & 0 & 0 & 0 & 0 & 0 & 0 & 0 & & & & & ( & 0 & & & 0 & & & & & & & & 7 \\
\hline & 0 & a & 0 & 0 & & & 0 & & & & & & & & & & & & & & & & & \\
\hline & 0 & 0 & 0 & 0 & & & & & & & & , & & & & & & & & 0 & & & & \\
\hline Caras: & 0 & 0 & 0 & 0 & 0 & 0 & 0 & 0 & 0 & 0 & 0 & 0 & 0 & 1 & 0 & 0 & 0 & 0 & 0 & 0 &  & 1 & 0 & \\
\hline otal & 167 & 41 & 186 & 114 & 165 & 361 & 439 & 349 & 366 & 419 & 349 & 632 & 741 & 575 & 545 & 833 & 535 & 985 & 568 & 593 & 557 & 6635 & 2885 & 9520 \\
\hline
\end{tabular}

808

$809 * 1$ Artificially introduced by local fisheries. 


\section{$812 \quad$ Appendix 3}

813 Appendix 3. Mean \pm SD of environmental factors at each sampling site.

\begin{tabular}{|c|c|c|c|c|c|c|c|c|c|c|c|c|c|}
\hline \multirow{2}{*}{$\begin{array}{l}\text { Sampling } \\
\text { site }\end{array}$} & \multirow{2}{*}{$\begin{array}{l}\text { Elevation } \\
(\mathrm{m})\end{array}$} & \multirow{2}{*}{$\begin{array}{l}\text { Water } \\
\text { temperature } \\
\left({ }^{\prime} \mathrm{C}\right)\end{array}$} & \multirow{2}{*}{$\begin{array}{c}\text { Gradient } \\
\text { of } \\
\text { riverbed } \\
(\%)\end{array}$} & \multirow{2}{*}{$\begin{array}{c}\text { Flow rate } \\
\left(\mathrm{m}^{3} / \mathrm{s}\right)\end{array}$} & \multirow{2}{*}{$\begin{array}{l}\text { River width } \\
\text { (m) }\end{array}$} & \multirow{2}{*}{$\begin{array}{l}\text { Water depth } \\
(\mathrm{cm})\end{array}$} & \multirow{2}{*}{$\begin{array}{l}\text { Current } \\
\text { velocity } \\
(\mathrm{cm} / \mathrm{s})\end{array}$} & \multicolumn{5}{|c|}{ Frequency of each substrate type (\%) } & \multirow{2}{*}{$\begin{array}{l}\text {-Presence/absence } \\
\text { of covers ( } 0 \text { or } 1)\end{array}$} \\
\hline & & & & & & & & Sand & Gravel & Cobble & Boulder & Bed rock & \\
\hline 1 & 650 & 14.8 & 0.03 & 0.05 & $3.0 \pm 1.4$ & $17.4 \pm 16.4$ & $10.5 \pm 12.2$ & $0.06 \pm 0.21$ & $0.61 \pm 0.31$ & $0.20 \pm 0.18$ & $0.01 \pm 0.03$ & $0.13 \pm 0.32$ & $0.03 \pm 0.16$ \\
\hline 2 & 640 & 15.0 & 0.02 & 0.12 & $4.0 \pm 1.5$ & $11.5 \pm 6.9$ & $25.2 \pm 23.2$ & $0.04 \pm 0.08$ & $0.58 \pm 0.24$ & $0.22 \pm 0.16$ & $0.13 \pm 0.15$ & $0.03 \pm 0.13$ & $0.03 \pm 0.16$ \\
\hline 3 & 630 & 15.0 & 0.02 & 0.19 & $4.8 \pm 1.7$ & $19.3 \pm 17.4$ & $25.4 \pm 56.9$ & $0.23 \pm 0.38$ & $0.41 \pm 0.34$ & $0.15 \pm 0.20$ & $0.01 \pm 0.03$ & $0.20 \pm 0.29$ & $0.00 \pm 0.00$ \\
\hline 4 & 620 & 15.0 & 0.02 & 0.15 & $5.4 \pm 1.0$ & $27.5 \pm 19.0$ & $10.5 \pm 15.8$ & $0.04 \pm 0.08$ & $0.52 \pm 0.31$ & $0.19 \pm 0.17$ & $0.03 \pm 0.08$ & $0.23 \pm 0.35$ & $0.03 \pm 0.16$ \\
\hline 5 & 400 & 19.2 & 0.02 & 1.14 & $5.8 \pm 1.1$ & $57.4 \pm 32.5$ & $38.8 \pm 32.3$ & $0.01 \pm 0.04$ & $0.37 \pm 0.34$ & $0.15 \pm 0.18$ & $0.17 \pm 0.20$ & $0.30 \pm 0.37$ & $0.00 \pm 0.00$ \\
\hline 6 & 370 & 19.8 & 0.01 & 0.88 & $11.6 \pm 3.7$ & $32.3 \pm 31.8$ & $25.3 \pm 26.7$ & $0.06 \pm 0.18$ & $0.51 \pm 0.35$ & $0.24 \pm 0.23$ & $0.04 \pm 0.09$ & $0.16 \pm 0.35$ & $0.03 \pm 0.18$ \\
\hline 7 & 370 & 19.9 & 0.01 & 1.09 & $11.0 \pm 3.3$ & $32.6 \pm 24.6$ & $35.1 \pm 42.9$ & $0.04 \pm 0.12$ & $0.50 \pm 0.33$ & $0.26 \pm 0.24$ & $0.14 \pm 0.22$ & $0.06 \pm 0.19$ & $0.03 \pm 0.17$ \\
\hline 8 & 350 & 20.4 & 0.01 & 0.91 & $9.6 \pm 2.9$ & $49.9 \pm 42.5$ & $20.5 \pm 27.1$ & $0.06 \pm 0.15$ & $0.63 \pm 0.33$ & $0.18 \pm 0.19$ & $0.00 \pm 0.02$ & $0.13 \pm 0.31$ & $0.00 \pm 0.00$ \\
\hline 9 & 320 & 20.6 & 0.02 & 0.83 & $9.4 \pm 2.1$ & $27.6 \pm 17.0$ & $34.8 \pm 31.9$ & $0.02 \pm 0.08$ & $0.44 \pm 0.24$ & $0.41 \pm 0.20$ & $0.12 \pm 0.15$ & $0.00 \pm 0.00$ & $0.00 \pm 0.00$ \\
\hline 10 & 300 & 19.4 & 0.01 & 1.83 & $12.6 \pm 4.6$ & $53.3 \pm 44.4$ & $29.7 \pm 32.1$ & $0.03 \pm 0.13$ & $0.71 \pm 0.30$ & $0.17 \pm 0.18$ & $0.01 \pm 0.03$ & $0.08 \pm 0.26$ & $0.00 \pm 0.00$ \\
\hline 11 & 290 & 19.2 & 0.01 & 1.84 & $11.6 \pm 3.4$ & $33.3 \pm 29.6$ & $50.6 \pm 40.8$ & $0.03 \pm 0.12$ & $0.64 \pm 0.31$ & $0.23 \pm 0.22$ & $0.02 \pm 0.09$ & $0.08 \pm 0.25$ & $0.00 \pm 0.00$ \\
\hline 12 & 280 & 19.0 & 0.00 & 0.87 & $15.5 \pm 2.0$ & $25.1 \pm 16.2$ & $24.8 \pm 22.4$ & $0.08 \pm 0.17$ & $0.66 \pm 0.27$ & $0.20 \pm 0.20$ & $0.02 \pm 0.07$ & $0.03 \pm 0.15$ & $0.00 \pm 0.00$ \\
\hline 13 & 280 & 18.3 & 0.01 & 1.19 & $13.1 \pm 3.0$ & $28.5 \pm 18.4$ & $33.6 \pm 22.8$ & $0.08 \pm 0.16$ & $0.49 \pm 0.25$ & $0.31 \pm 0.21$ & $0.06 \pm 0.11$ & $0.06 \pm 0.21$ & $0.00 \pm 0.00$ \\
\hline 14 & 260 & 20.5 & 0.01 & 2.27 & $35.8 \pm 12.6$ & $62.8 \pm 39.4$ & $11.9 \pm 7.3$ & $0.18 \pm 0.34$ & $0.69 \pm 0.39$ & $0.05 \pm 0.09$ & $0.00 \pm 0.02$ & $0.08 \pm 0.26$ & $0.08 \pm 0.27$ \\
\hline 15 & 250 & 19.2 & 0.01 & 2.02 & $12.3 \pm 3.8$ & $71.0 \pm 36.4$ & $27.8 \pm 18.2$ & $0.18 \pm 0.29$ & $0.53 \pm 0.36$ & $0.11 \pm 0.14$ & $0.03 \pm 0.12$ & $0.16 \pm 0.31$ & $0.27 \pm 0.45$ \\
\hline 16 & 220 & 19.9 & 0.01 & 1.68 & $19.8 \pm 2.5$ & $42.9 \pm 31.7$ & $21.5 \pm 22.2$ & $0.16 \pm 0.26$ & $0.34 \pm 0.26$ & $0.31 \pm 0.22$ & $0.10 \pm 0.14$ & $0.08 \pm 0.20$ & $0.03 \pm 0.18$ \\
\hline 17 & 200 & 20.0 & 0.01 & 3.62 & $13.9 \pm 3.0$ & $67.4 \pm 42.4$ & $44.0 \pm 37.1$ & $0.06 \pm 0.19$ & $0.34 \pm 0.31$ & $0.26 \pm 0.26$ & $0.06 \pm 0.14$ & $0.27 \pm 0.35$ & $0.05 \pm 0.22$ \\
\hline 18 & 190 & 20.7 & 0.01 & 1.91 & $17.4 \pm 3.2$ & $35.7 \pm 16.6$ & $34.1 \pm 27.6$ & $0.02 \pm 0.08$ & $0.26 \pm 0.27$ & $0.34 \pm 0.27$ & $0.11 \pm 0.19$ & $0.27 \pm 0.38$ & $0.00 \pm 0.00$ \\
\hline 19 & 170 & 20.8 & 0.01 & 2.22 & $19.2 \pm 2.3$ & $38.6 \pm 33.2$ & $31.8 \pm 28.1$ & $0.04 \pm 0.17$ & $0.71 \pm 0.34$ & $0.12 \pm 0.15$ & $0.02 \pm 0.06$ & $0.12 \pm 0.29$ & $0.00 \pm 0.00$ \\
\hline 20 & 160 & 20.7 & 0.00 & 3.50 & $25.9 \pm 3.8$ & $44.9 \pm 27.8$ & $33.2 \pm 31.2$ & $0.07 \pm 0.19$ & $0.43 \pm 0.29$ & $0.35 \pm 0.25$ & $0.06 \pm 0.11$ & $0.09 \pm 0.23$ & $0.00 \pm 0.00$ \\
\hline 21 & 160 & 19.5 & 0.01 & 3.53 & $24.1 \pm 3.5$ & $90.9 \pm 60.3$ & $18.3 \pm 20.0$ & $0.11 \pm 0.26$ & $0.46 \pm 0.39$ & $0.21 \pm 0.28$ & $0.07 \pm 0.16$ & $0.15 \pm 0.32$ & $0.00 \pm 0.00$ \\
\hline
\end{tabular}

814

815 




家
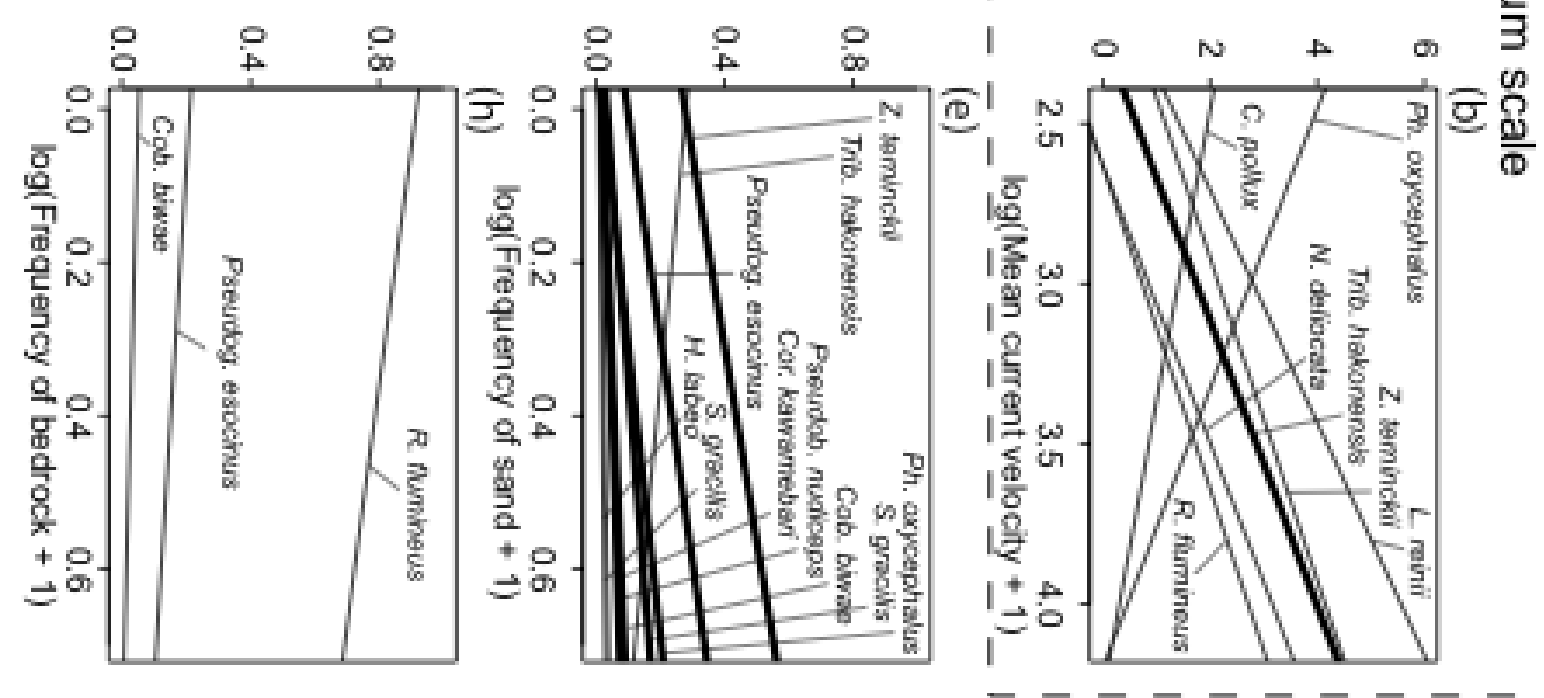

817


$-------$
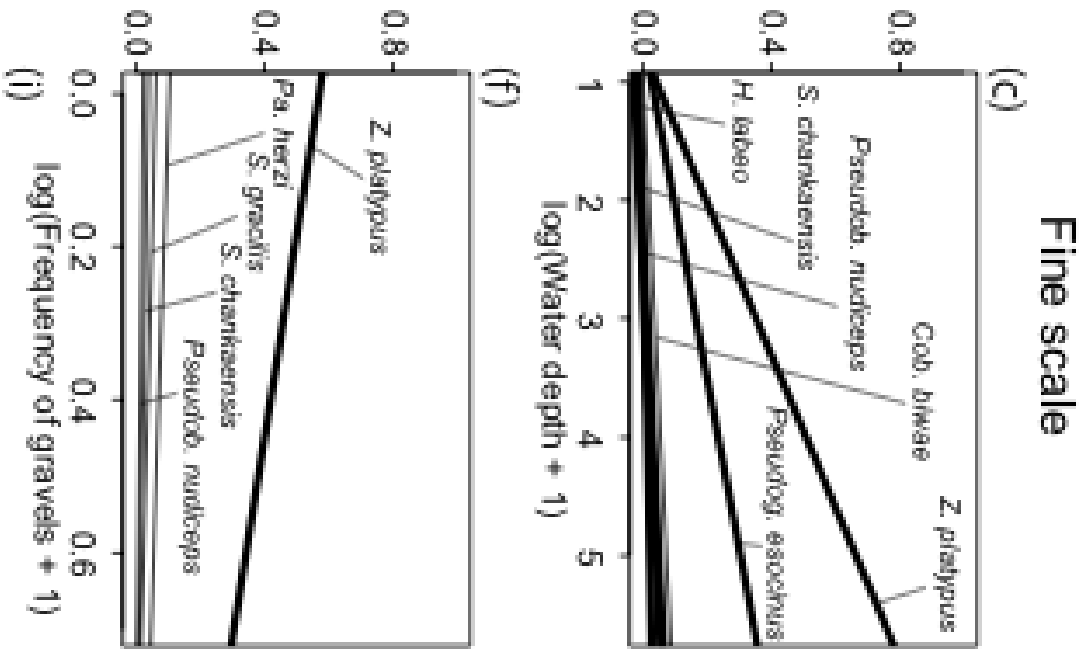
818 Appendix 4. Relationships between environmental factors and the number of observed individuals

819 at medium (a), (b) and fine (c)-(i) scales. Fish species for which the total number of observed

820 individuals was $<20$ are omitted. In (a)-(h), lines show significant regression lines with and without

821 Bonferroni adjustment between environmental factors and the observed number of individuals of

822 each species. Line types show the significance of correlation by linear regression: thin lines indicate

$823 P<0.05$ and bold lines indicate $P<0.05$ with Bonferroni adjustment. In (i), circles show means and

824 bars denote the SDs for each species. Black and grey circles indicate the existence of a significant

825 difference with $P<0.05$ with and without Bonferroni adjustment, respectively, by ANOVA testing. 